\title{
ANALYSIS OF TWO-WELL TRACER TESTS WITH A PULSE INPUT
}

PREPARED BY

LYNN W. GELHAR

FOR

ROCKWELL INTERNATIONAL CORPORATION ROCKWELL HANFORD CPERATIONS ENERGY SYSTEMS GROUP

BASALT WASTE ISOLATION PROJECT

P.O. BOX 800

RICHLAND, WA 99352

APRIL 1982 


\section{DISCLAIMER}

This report was prepared as an account of work sponsored by an agency of the United States Government. Neither the United States Government nor any agency Thereof, nor any of their employees, makes any warranty, express or implied, or assumes any legal liability or responsibility for the accuracy, completeness, or usefulness of any information, apparatus, product, or process disclosed, or represents that its use would not infringe privately owned rights. Reference herein to any specific commercial product, process, or service by trade name, trademark, manufacturer, or otherwise does not necessarily constitute or imply its endorsement, recommendation, or favoring by the United States Government or any agency thereof. The views and opinions of authors expressed herein do not necessarily state or reflect those of the United States Government or any agency thereof. 


\section{DISCLAIMER}

Portions of this document may be illegible in electronic image products. Images are produced from the best available original document. 


\section{Summary}

Dispersion of a conservative solute which is introduced as a pulse in the recharge well of a two-well flow system is analyzed using the general theory for longitudinal dispersion in nonuniform flow along streamines. Results for the concentration variation at the pumping well are developed using numerical integration and are presented. in the form of dimensionless type-curves which can be used to design and analyze tracer tests.

Application of the results is illustrated by analyzing the preliminary tracer test run at boreholes $D C 7 / 8$ on the Hanford site by Science Applications, Inc., a subcontractor to Rockwell. Hanford Operations, in December 1979. 


\section{GENERAI THEORY}

The objective of this analysis is to describe the tracer concentration which evolves in the pumping well of a two-well (pumping-recharge) flow system (see Figure 1) when an instantaneous pulse (slug) of conservative tracer is introduced in the recharge well. The streamine pattern for steady flow in a homogeneous confined aquifer is used in conjunction with the general theoretical results of Gelhar and Collins (1971) for longitudinal dispersion in nonuniform flows. With a pulse input their general result for the concentration (Equation 25) is

$$
\begin{aligned}
& c(s, t)=\frac{m}{u(s) \sqrt{4 \pi \alpha \omega}} \exp \left[-\eta^{2} / 4 \alpha \omega\right] \\
& \mathbf{s}=\text { distance along streamline } \\
& t=\text { time } \\
& \alpha=\text { longitudinal dispersivity } \\
& \eta=\tau(s)-t \\
& \tau(s)=\int_{s_{0}}^{s} d s / u(s) \text {, travel time to } s \\
& \omega(t)=\int_{s_{0}}^{\bar{s}} d s /[u(s)]^{2} \\
& \bar{s}(t)=\text { mean location of the pulse at time } t \\
& u(s)=\text { seepage velocity } \\
& m \text { = mass of tracer per net area of aquifer injected } \\
& \text { at } s=s_{0} \text { at time } t=0
\end{aligned}
$$

Equation (1) is applied along each streamline identified by the 


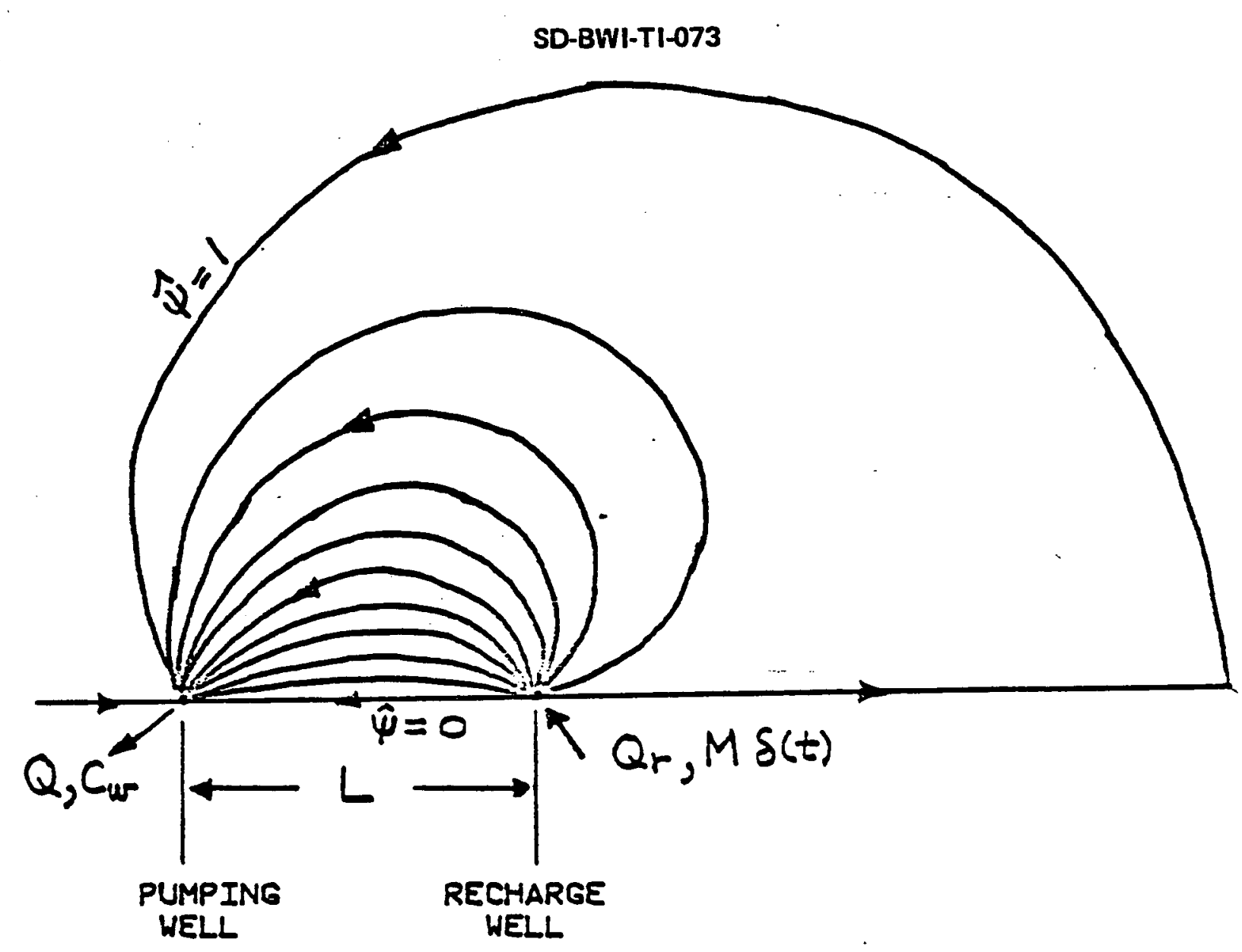

FIGURE 1. STREAMLINE PATTERN FOR TWO-WELL FLOW SYSTEM WITH O $/ 0_{p}=2 / 3$.

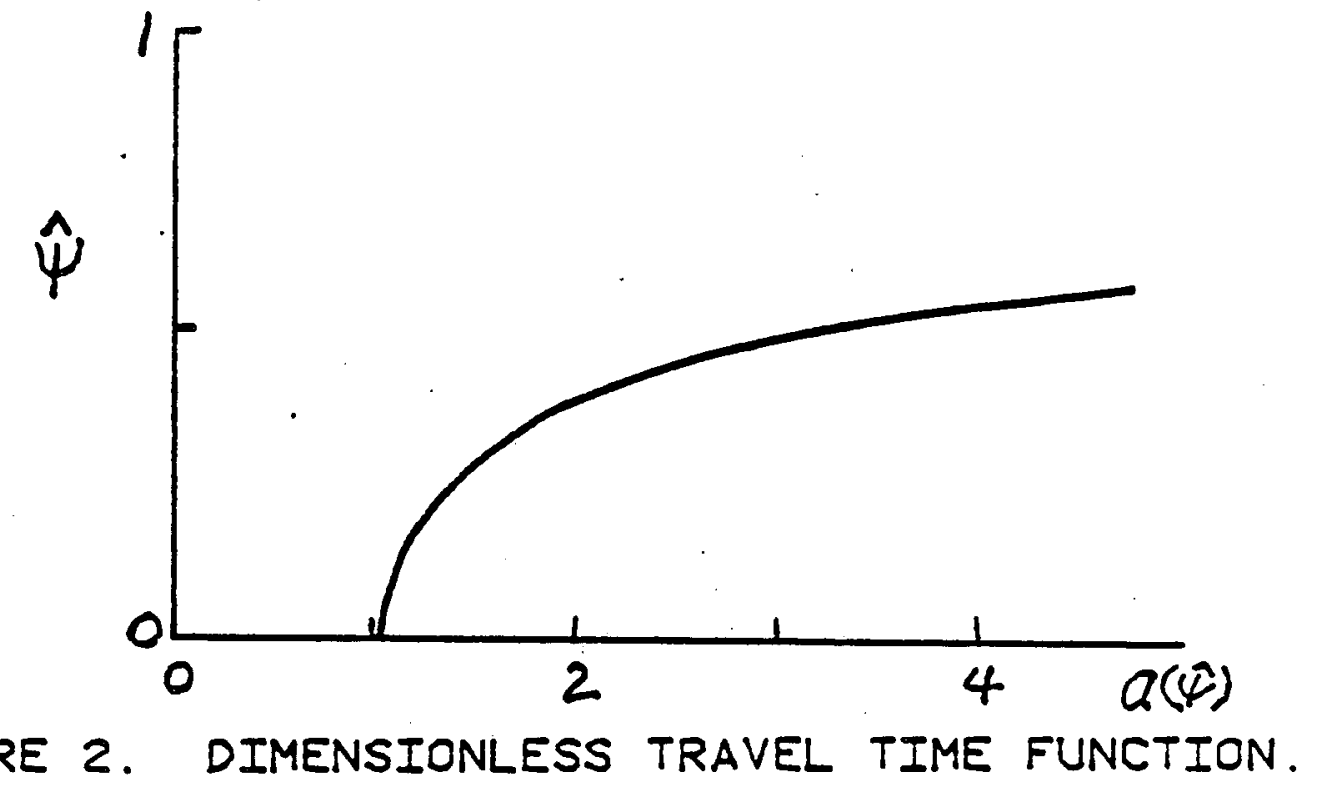

6 
value of the stream function $\psi$; therefore the velocity u depends on $\psi$ and as a result, $\tau(s, \psi)$ and $\omega(t, \psi)$. These flow integrals can be evaluated either analytically or graphically as described in the next section. The coefficient $m / u\left(s_{0}\right)$ in (1) is evaluated by noting that at the recharge well

$$
\begin{aligned}
u\left(s_{0}\right) & =Q /\left(2 \pi r_{w} \cap H\right) \\
Q_{p} & =\text { recharge rate } \\
r_{w} & =\text { well radius } \\
n & =\text { effective porosity } \\
H & =\text { aquifer thickness } \\
m & =M / 2 \pi r_{\text {w }} n \text { H } \\
M & =\text { mass of tracer injected } \\
m / u\left(s_{l}\right) & =M / Q_{r}
\end{aligned}
$$

The concentration in the pumping well is found by calculating the flow-weighted concentration as the following integral:

$$
c_{\omega}=\frac{2 H}{Q} \int_{\psi=0}^{Q / 2 H}(M / \beta Q)(4 \pi \alpha \omega)^{-1 / 2} \exp \left[-(\tau-t)^{2} / 4 \alpha \omega\right] d \psi
$$

where $\beta=Q_{p} / Q$. In this integral the flow integrals $\tau$ and $\omega$ depend on the stream function, $\Psi$.

2. EVALUATION OF FLOW INTEGRALS AND WELL CONCENTRATION

For the case of equal recharge and discharge rates $(\beta=1)$, the integrals for $\tau$ and $\omega$ can be evaluated analytically from the velocity variation along a given streamline. The details of this 
analysis are given in Appendix $A$; the results for $\tau$ and $\omega$ are given by (A3) and (A4) expressed in dimensionless form as

$$
a(\hat{\psi})=\frac{Q \tau_{\omega}}{n H L^{2}} \quad, \quad b(\bar{\xi}, \hat{\psi})=\left(\frac{Q}{H H}\right)^{2} \frac{\omega}{L^{3}}
$$

where $\tau_{u}$ is the travel time to the pumping well. The well concentration is evaluated using these dimensionless forms and the variable of integration $\hat{\psi}=\psi /(B Q / 2 H)$. Then, for the upper half plane in Figure 1 , the flow from the recharge well is represented by the range $0 \leqslant \hat{\psi} \leqslant 1$. Furthermore, the concentration will always be zero for the streamlines with $\hat{\psi}>1$ because lateral dispersion is neglected. Then, using (3) in (2),

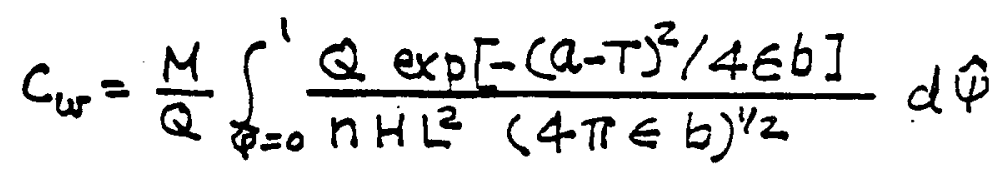

$$
\begin{aligned}
& \hat{C}=\frac{n H L^{2}}{M} c_{\omega}=\int_{\hat{\psi}=0}^{1} \frac{\exp \left[-(a-T)^{2} / 4 \in b\right]}{(4 \pi \in b)^{4 / 2}} d \hat{\psi} \\
& T=\frac{Q t}{n H L^{2}}, \quad \epsilon=\frac{\alpha}{L}
\end{aligned}
$$

The integral in (4) was evaluated numerically. using $a$ and $b$ from Appendix A; a listing of the computer program is included in Appendix $C$.

For the case of unequal flow $\tau$ and $\omega$ were determined graphically from a flow net constructed for the case $\beta=2 / 3$ as described in Appendix $B$. 


\section{SD-BWI-TI-073}

The limiting result for no dispersion in (4) is found by noting that, as $\in \rightarrow 0$,

$$
\frac{\exp \left[-(a-T)^{2} / 4 \in b\right]}{(4 \pi \in b)^{1 / 2}} \rightarrow \delta(a-T)
$$

where $\delta(x)$ is the Dirac delta function. Changing the variable of integration to a $(\hat{\psi}),(4)$ becomes

$$
\hat{c}=\int_{a(0)}^{\infty} \delta(a-T) \frac{d \hat{\psi}}{d a} d a= \begin{cases}\left.\frac{d \hat{\psi}}{d a}\right|_{a=\tau,} & T>a(0) \\ 0, T<a(0) & T<a(0)\end{cases}
$$

The function $a(\hat{\psi})$ is simply the dimensionless travel time to the pumping well along a given streamline $\hat{\psi}$; the general form of this function is shown in Figure 2. The non-zero portion of (5) can be evaluated by taking

$$
\frac{d \hat{\psi}}{d a}=\left(\frac{d a}{d \hat{\psi}}\right)^{-1}
$$

and $\hat{c}(T)$ is then determined by taking $T=a(\hat{\psi})$ and $d a / d \hat{\psi} \mid \hat{\psi}_{1}$ where $\hat{\psi}_{1}$ is an assigned value of $\hat{\psi}$.

\section{RESULTS}

Numerical evaluation of the concentration in the pumping well as given by (4) was carried out using the computer program listed in Appendix $c$. Several zuns were made to test the effects of model parameters and approximations. The results are listed in tabular form in Appendix $D$.

Figure 3 shows a comparison of the graphically based 
FIGURE 3. COMPARISON OF EXACT AND GRAPHICAL FLOWNET CALCULATIONS.

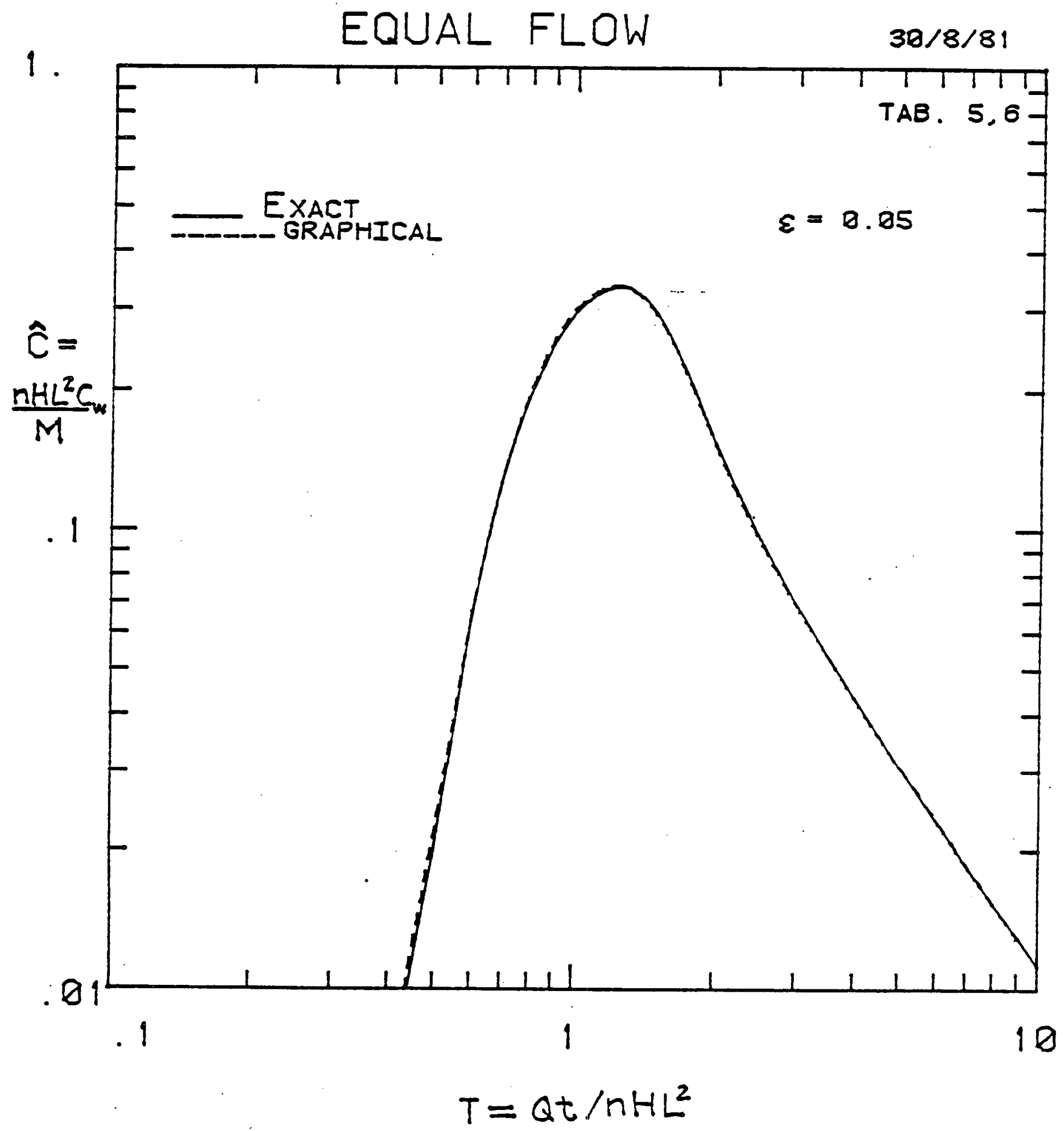




\section{SD-BWI-TI-073}

results using $m=1$ (Appendix $B$ ) and the exact result using the equations from Appendix A. The excellent agreement demonstrates the adequacy of the graphical approximation with $\mathrm{m}=1$ in (B2); that value was used in all subsequent calculations. Figure 4 illustrates the effect of using the approximate form of (B2); some difference is observed at lower concentrations for the rising limb of the curve with the large value of $\epsilon=0.2$. For smaller $\epsilon$ the differences are generally smaller, as shown in Figure 3. The effects the increment $\Delta \hat{\psi}$ used to approximate the integral in (4) are illustrated in Figure 5. When $\epsilon=0.01$, the larger $\Delta \hat{\psi}=0.05$ produces oscillations in the tail of the curve, but these are eliminated when $\Delta \hat{\psi}=0.01$; for $\epsilon=0.2$ the results are non-oscillatory when $\Delta \hat{\psi}=0.05$. Generally the oscillations are eliminated if $\Delta \hat{\psi} \leqslant \epsilon$.

The overall results are summarized in Figures 6 and 7 ; the unequal flow case (Fig. 7 with $\beta=2 / 3$ ) corresponds to the SAI tracer test of December 1979. These results show that the dispersion parameter $\epsilon=\alpha / L$ affects the rising part of the curve and the peak but not the tail. This point is further demonstrated by the behavior the non-dispersive solution using (5) and (A5) as shown in Figure 6. This shows that all of the results approach the non-dispersive analytical result for large time, and further demonstrates the adequacy of the numerical procedure. Generally, the breakthrough curves are characterized by a steep rising limb and an elongated tail as shown in the linear plots of Figure 8. The log-log plots (Figure 6 and 7 ) are 
FIGURE 4. COMPARISON OF EXACT CALCULATION WITH APPROXIMATION USING EO. B2.

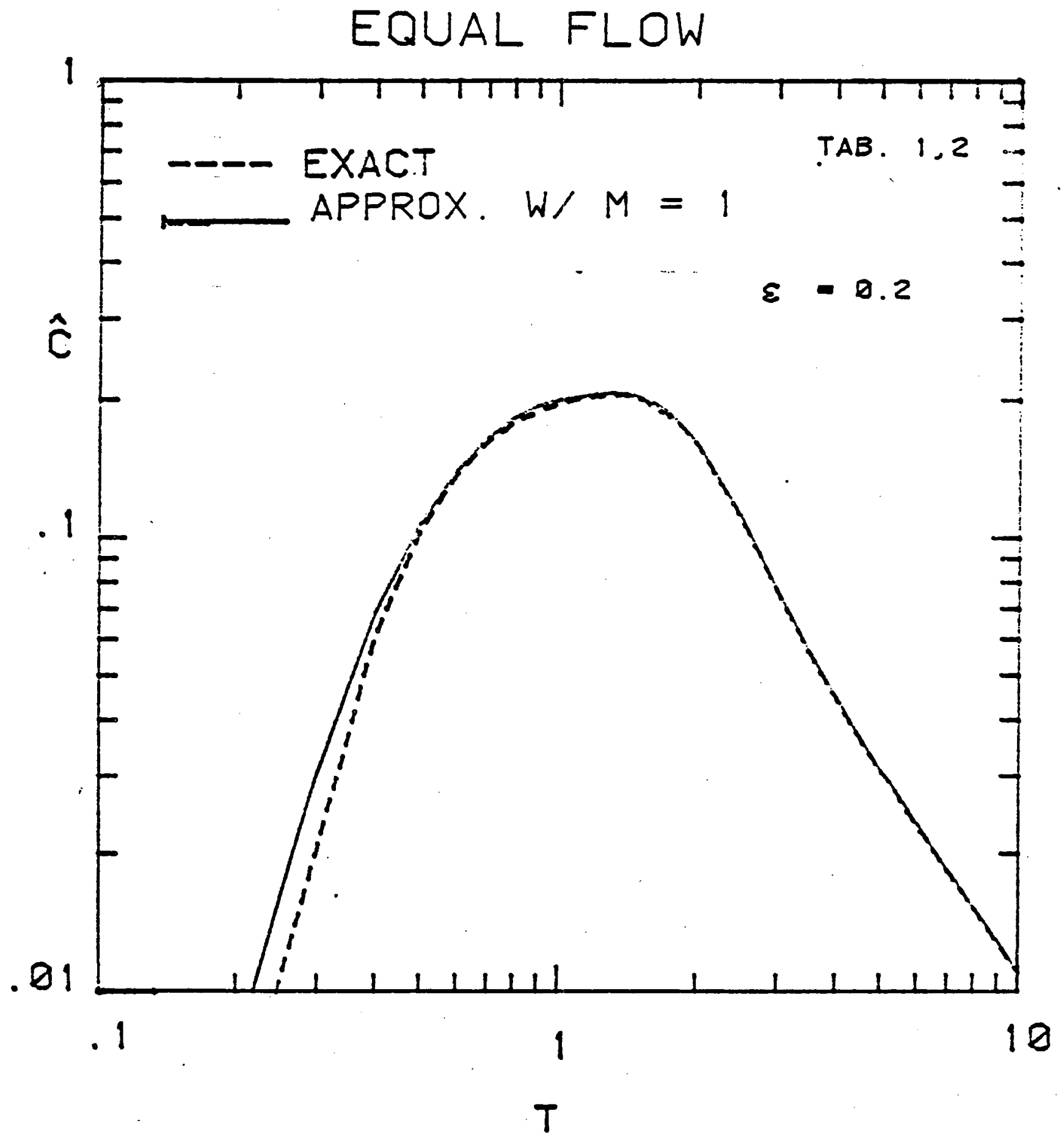


SD-BWI-TI-073

FIGURE 5. EFFECT OF INTEGRATION INCREMENT.

$\hat{c}$

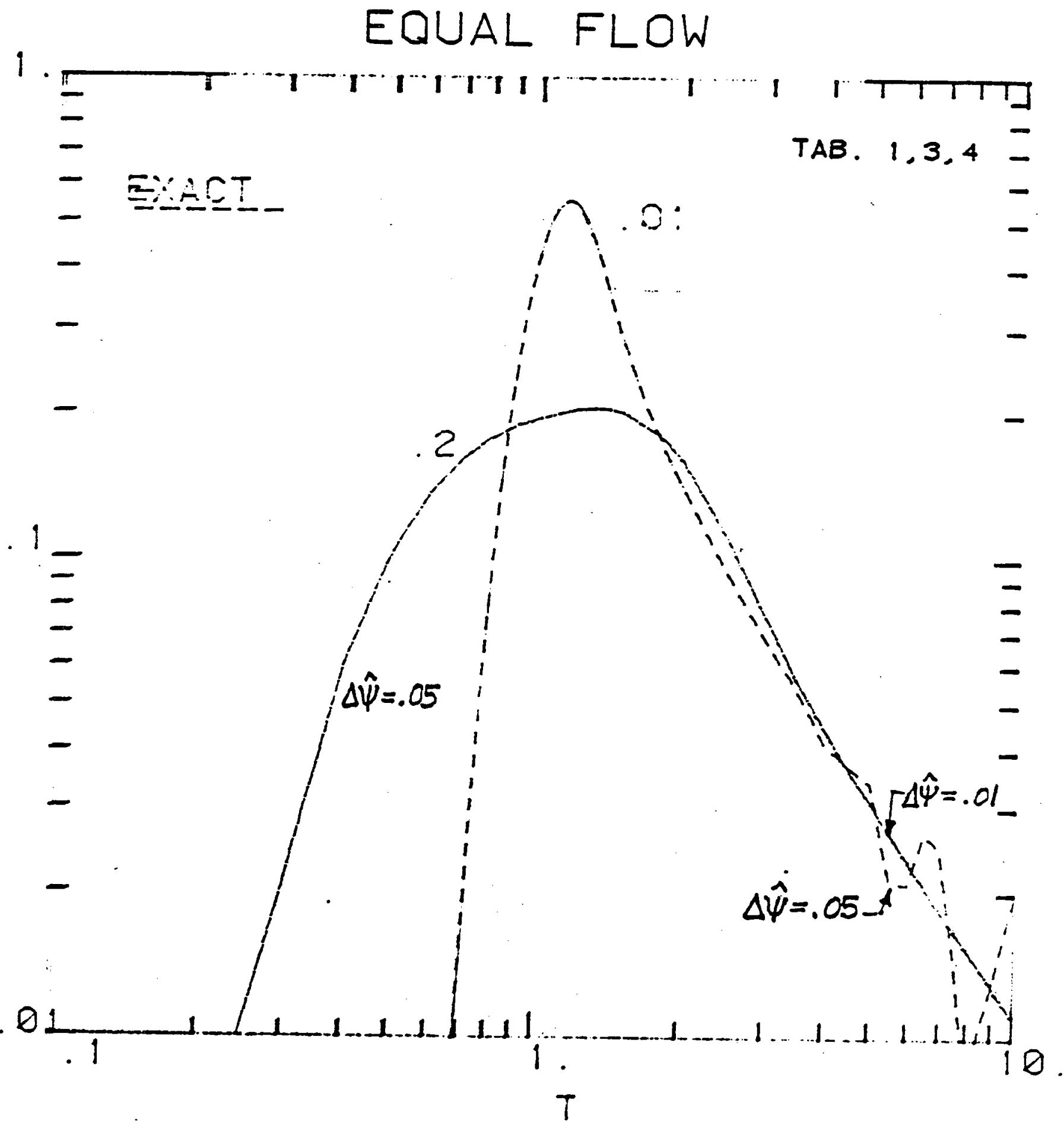


FIGURE 6. TYPE-CURVES FOR TWO-WELL PULSE INPUT TEST WITH EOUAL FLOW.

EOUAL FLOW

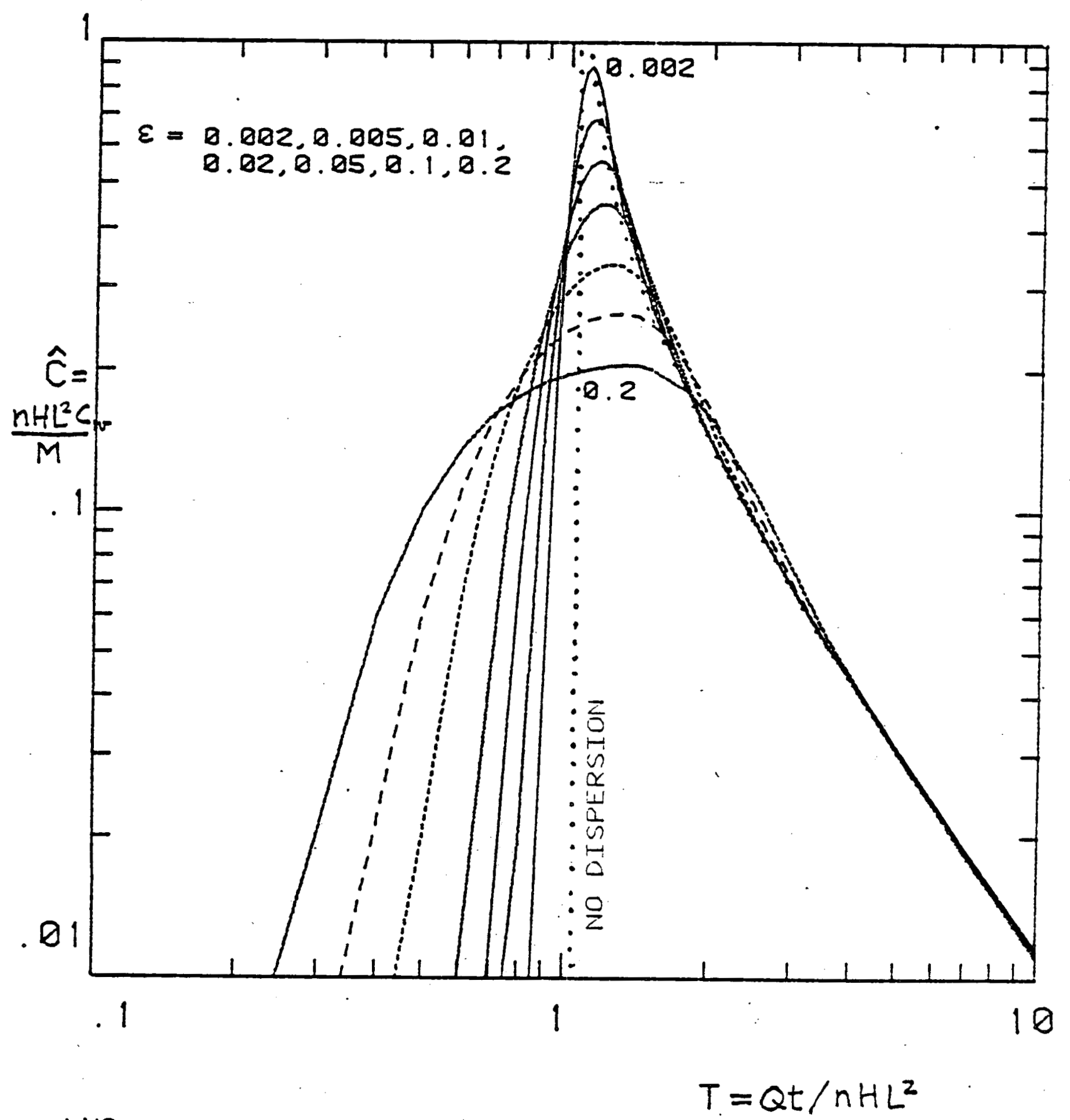

LWG. 
SD-BWI-TI-073

FIGURE 7. TYPE-CURVE FOR TWO-WELL PULSE INPUT WHEN THE RECHARGE RATE IS TWO-THIRDS OF THE DISCHARGE RATE, 0.

1. UNEOUAL FLOW

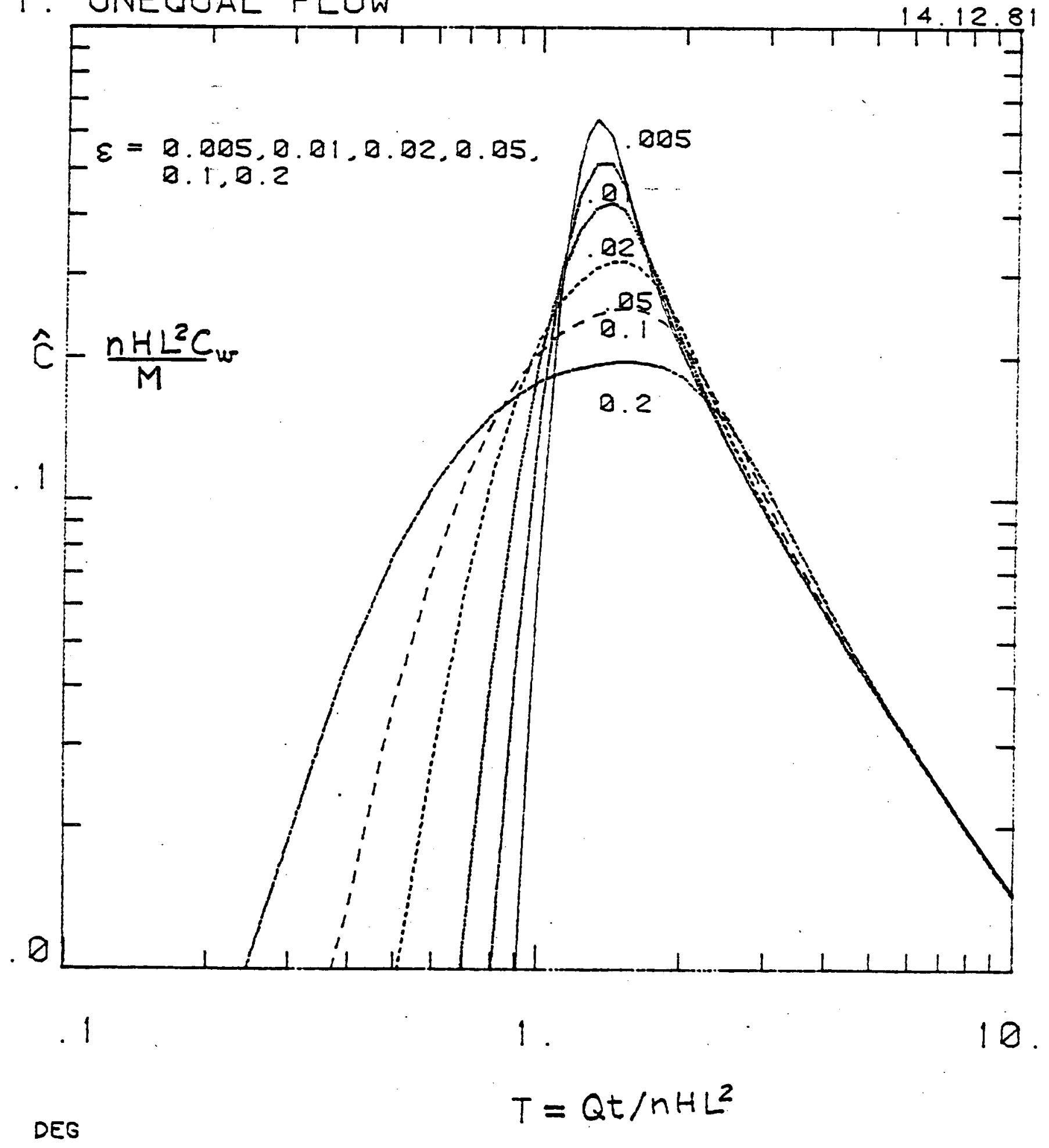

15 
FIGURE 8. PULSE INPUT TYPE-CURVES PLOTTED WITH LINEAR SCALES.

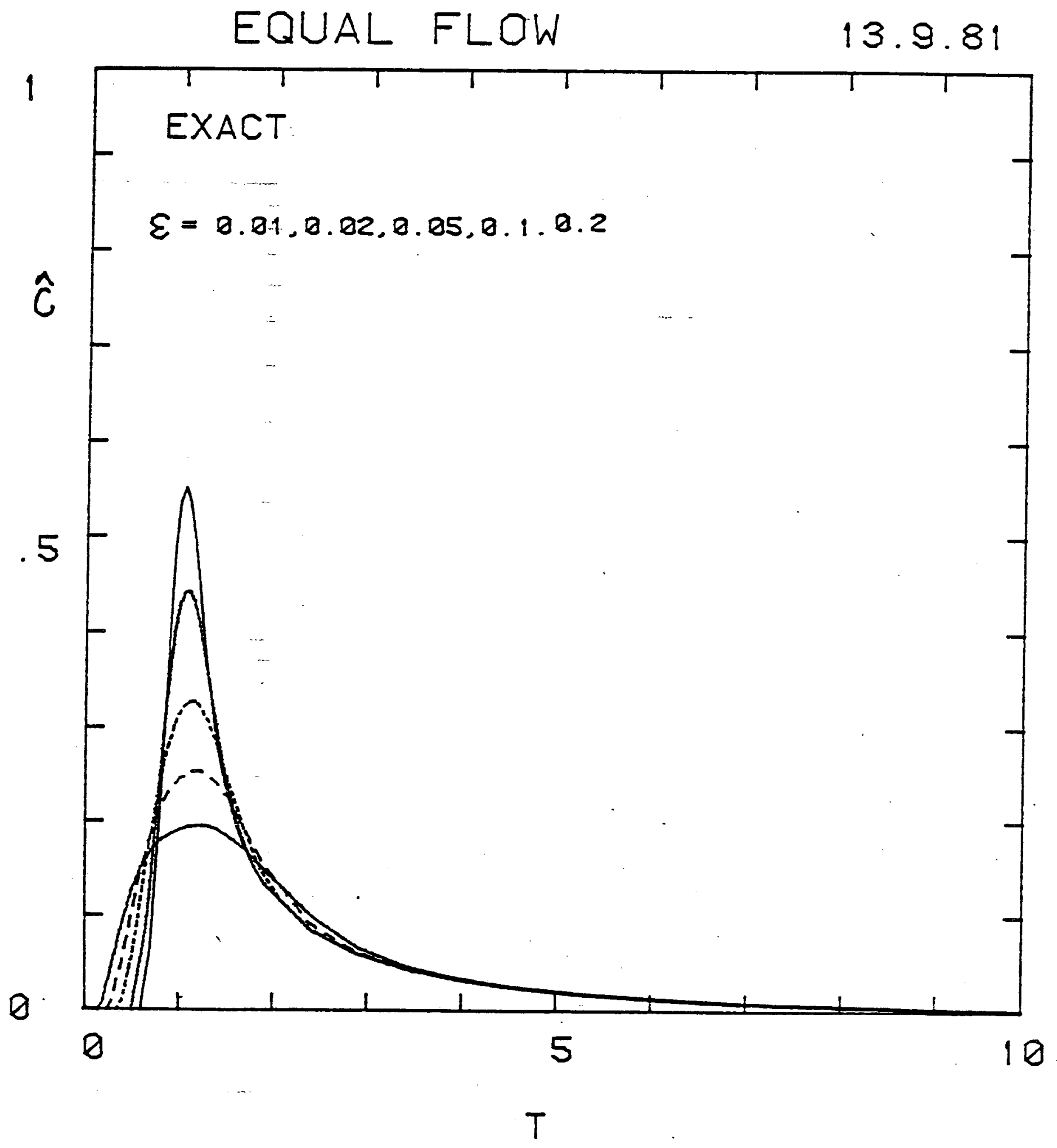

DEG 


\section{SD-BWI-TI-073}

convenient for estimating the dispersivity and effective porosity from tracer test data as illustrated in the following section.

\section{APPLICATION METHODOLOGY}

The procedure for interpretation of tracer test data using the results of the above analysis is illustrated by analyzing the test conducted by Science Applications, Inc. (SAI) at DC7/8 in December, 1979. Since some of the conditions of that test were not fully defined, the results of this interpretation are considered to be preliminary; this example is present primarily to illustrate the procedures which can be used to analyze such tests.

The SAI test was reanalyzed using the type curves in Figure 7. The flow rates for the test were estimated using the average rates implied for the period 15:13 - 23:00 in Table G4 (p. G-38, SAI draft report); $Q_{r}=2.31$ gpm (injection rate) and $Q=$ 3.42 gpm (pumping rate) or $Q_{r} / Q=\beta \cong 2 / 3$. Based on these rates and estimates of the volume in the borehole flow conduits and connecting plumbing the following travel times to and from the test horizon were estimated:

$$
\begin{aligned}
& \text { time down in injection well }=153 \mathrm{~min} . \\
& \text { time up in pumping well }=258 \mathrm{~min} \text {. }
\end{aligned}
$$

These times were subtracted from the observed times to give the actual elapsed time since the tracer entered the formation. Also the elapsed time was corrected to correspond to a constant pumping rate of 3.42 gpm based of the actual metered volume in 
Table G4. After these time corrections were made, the actual data points in Figure 21 (SAI draft report) were plotted with the estimated background of 20 counts subtracted; the corrected data are shown in Figure 9, a log-log plot of the same scale (K\&E $4673232 \times 3$ cycles) as the dimensionless type-curves in Figure 7 for $\beta=2 / 3$. Overlaying the data on the type-curve, we find a reasonable fit for 6 in the range 0.02 to 0.05 ; using $\epsilon=0.035=\alpha / L$ and $L=56 \mathrm{ft}$. , the indicated longitudinal dispersivity is

$$
\alpha=0.035(56)=1.96 \mathrm{ft} \text {. }
$$

Matching the time scales in Figure 9 ,

$$
T=1=Q t / \mathrm{nHL}^{2}, t(\text { hours })=1.18 \mathrm{hrs}
$$

yields the effective thickness

$$
n H=Q t / L^{2}=0.0105 \mathrm{ft} \text {. }
$$

The data in Figure 9 seem to show some systematic departures from the theoretical type-curve. This could be a reflection of experimental ambiguities such as the following:

1) The background concentration is n t clearly determined and small changes in this level could drastically alter the low concentration parts of the curve.

2) Unobserved flow rate variations during the period that the tracer was passing the sensor would distort the shape the curve.

3) Uncertainty about the volume in the connecting conduits could introduce errors in the travel time correction and alter the shape of the curves. 


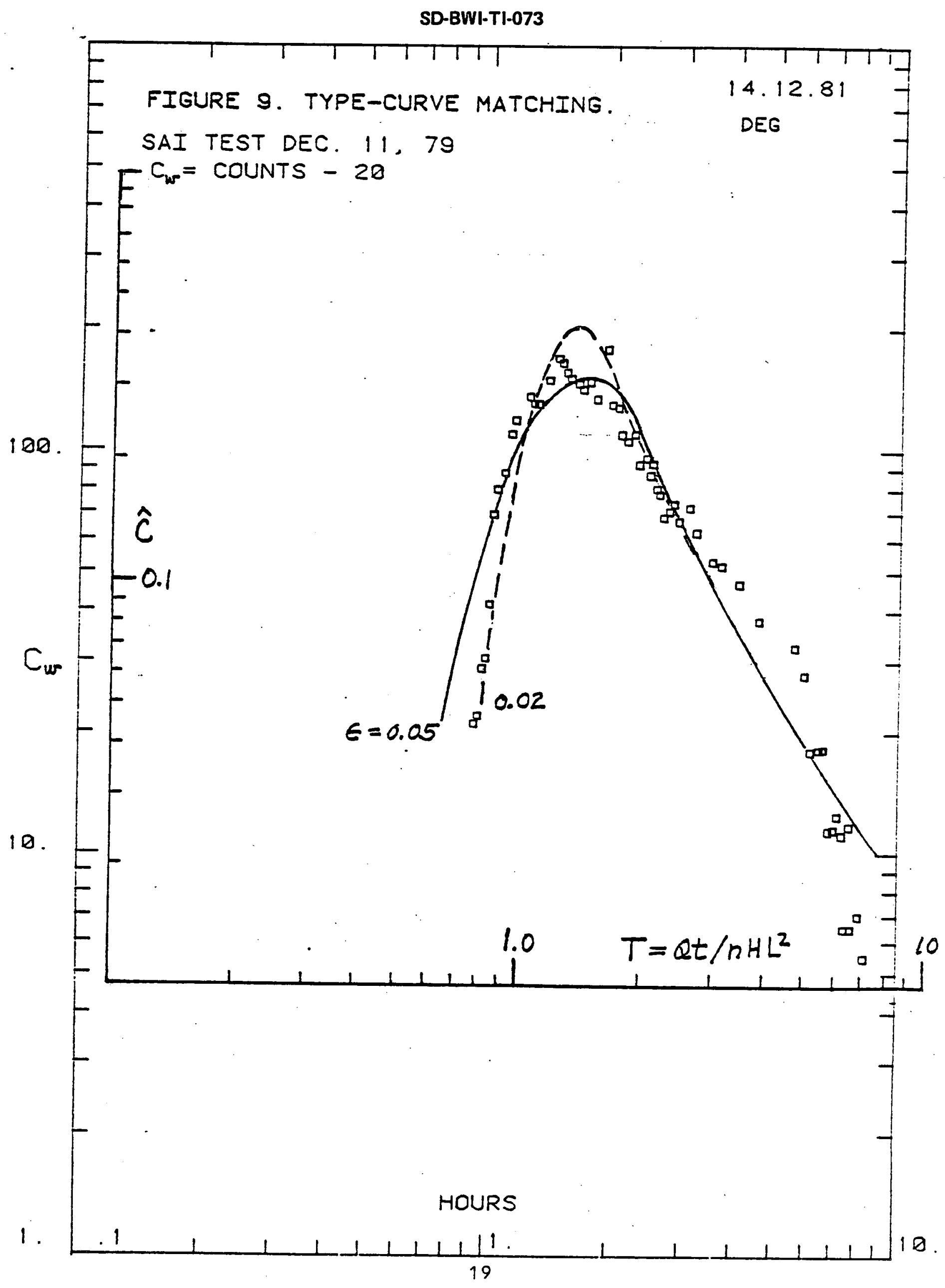




\section{SD-BWI-TI-073}

The differences in Figure 9 could also indicate that the tested zone does not behave as a homogeneous, constant thickress aquifer. If other sources of errors were eliminated, departures on the tail of the curve would be diagnostic of that possibility because that part of the type-curves is determined solely by convection; i.e., the travel time distribution.

Calculations for the SAI test were also made using the approximate method developed in Appendix $H$ of the SAI draft report. From Figure 9 the peak time $t=I .5$ hrs and the time to rise from one-half of the peak is $t=0.45$ hrs. Then using equation (15) of Appendix $\mathrm{H}$ with $E=0.202, G=0.0488(\beta=2 / 3)$

$$
\begin{aligned}
& \frac{\alpha}{L}=\frac{1}{4 \ln 2 G F^{2}(\Delta t)^{2}}=0.0271 \\
& \alpha=1.52 \mathrm{ft} .
\end{aligned}
$$

and from equation (14) with $Q=3.42 \mathrm{gpm}$,

$$
n H=\frac{Q t_{p}}{2 \pi L^{2} F}=0.0103 \mathrm{ft} .
$$

These results show good agreement with those from the type-curve approach and indicate that the approximate method in the SAI report is reliable. Of course, the type curve method has the advantage that it uses the complete breakthrough curve.

The type-curves of Figures 6 and 7 can also be used to design tracer tests; using estimates of $\epsilon=\alpha / L$, the actual concentration level that will result from a given mass of tracer $M$ can be determined in terms of the effective thickness nH and the 


\section{SD-BWI-TI-073}

well spacing $L ;$ i.e., $c_{\Psi}=\mathrm{M} \hat{c} / \mathrm{nHL}^{2}$.

\section{COMMENTS AND RECOMMENDATIONS}

These results demonstrate the feasibility of the two-well tracer test with a pulse input as a method of determining effective porosity and dispersivity. This type of test has the advantage that the shape of the breakthrough curve is very sensitive to the dispersivity. This is in contrast to the more frequently used step input (Webster et al, 1970; Grove and Beetem, 1971; Robson, 1974; Mercer and Gonzales, 1981) in which dispersion affects the shape of the curve only in the initial low concentration portion of the curve.

The type-curves developed here provide a simple method of designing and analyzing two-well pulse input tracer tests.

The method of analysis used here presumes that $\alpha / \tau$ is relatively small; results in Gelhar and Collins (1971) indicate that the method should be reasonably accurate for $\alpha / L<0.1$. If the method is to be used for larger values of $\alpha / L$, some comparative testing with numerical solutions is suggested. However, it should be recognized that, under those conditions, (large $\alpha / L$ ) other factors such as displacement dependent dispersivity and non-Fickian effect (Gelhar et al, 1979) may complicate the interpretation. Also, transverse dispersion is neglected in this analysis; this assumption is reasonable for small $\alpha / L$ because then the dispersion effect occurs primarily along the more direct streamlines for which the Eronts will be nearly perpendicular to the streamlines. For larger $\alpha / L$ the 


\section{SD-BWI-TI-073}

dispersion effect along a wider range of streamlines becomes important; numerical testing would also be required in this case. When $\alpha / L$ is large, a finite difference or finite element solution should be routine because a relatively coarse grid could be used. The type-curves for the pulse input can also be used to treat other inputs by convolution. In particular, this would apply to recirculating tests in which the pulse is routed through the aquifer several times. This aspect is important in the Hanford tests because analysis of the secondary peaks would provide a check on the borehole travel time. Some preliminary work has been done on numerical convolution of the pulse input results. It is recommended that this be developed for analysis of the Hanford data. 


\section{SD-BWI-TI-073}

\section{REFEREHCES}

Gelhar, L. W., and M. A. Collins, General analysis of longitudinal dispersion in nonuniform flow, Water Resources Res., $7(6), 1511-1521,1971$.

Gelhar, L. W., A. L. Gutjahr, and R. I. Naff, Stochastic analysis of macrodispersion in a stratified aquifer, Water Resources Res., 15(6), 1387-1397, 1979.

Grove, D. B., and W. A. Beetem, Porosity and dispersion constant calculations for a fractured carbonate aquifer using the two-well tracer method, Water Resources Res., 7(1); 128-134, 1971.

Mercer, J. W., and D. Gonzalez, Geohydrology of the proposed Waste Isolation Pilot Plant in southeastern Hew Mexico, New Mexico Geological Society Special Publication 10, 123-131, 1981.

Robson, S. G., Feasibility of water-quality modeling illustrated by application at Barstow, California, Water Resour. Invest. Rep. 46-73, U. S. Geol. Survey, Menlo Park, Cal., 66 pp.. 1974.

Webster, D. S., J. F. Proctor, and I. W. Marine, Two-well tracer test in fractured crystalline rock, U. S. Geol: Survey, Water Supply Paper 1544-I, 22 pp.. 1970. 


\section{SD-BWI-TI-073}

\section{APPENDIX A \\ $\tau$ and $\omega$ for the Equal Flow Case}

When $Q=Q_{r}$ it is easily shown that the streamlines are circular arcs. In that case the flow is conveniently described in the polar coordinate system shown in Figure A-1. The piezometric head h for steady flow in this system is

$$
\begin{aligned}
& n=\frac{Q}{4 \pi T_{r}} \ln \left(r_{1} / r_{2}\right)^{2} \\
& T_{p}=\text { transmissivity } \\
& r_{1}^{2}=(x+l)^{2}+y^{2}, x=-R \sin \gamma \\
& r_{2}^{2}=(x-l)^{2}+y^{2}, y=R \cos \gamma-B
\end{aligned}
$$

and using the Darcy equation, seepage velocity along the streamline is

$$
v_{\gamma}=-\frac{T r}{n H R} \frac{\partial h}{\partial \gamma}=-\frac{Q}{4 \pi n H R}\left(\frac{1}{r_{1}^{2}} \frac{\partial r_{1}^{2}}{\partial \gamma}-\frac{1}{r_{2}^{2}} \frac{\partial r_{2}^{2}}{\partial \gamma}\right)
$$

After extensive algebraic manipulation, this reduces to

$$
v_{\gamma}=\frac{2 Q R \sin ^{3} \phi}{\pi n H L^{2}(\cos \gamma-\cos \phi)}
$$

Using this velocity in the travel time integral

$$
\begin{aligned}
\tau & =\int_{s_{0}}^{s} \frac{d s}{U(s)}=\int_{\gamma=-\phi}^{\gamma} \frac{R d \gamma}{v_{\gamma}} \\
& =\frac{n H L^{2}}{Q} \frac{\pi}{2 \sin ^{3} \phi}(\sin \gamma+\sin \phi-(\gamma+\phi) \cos \phi)
\end{aligned}
$$




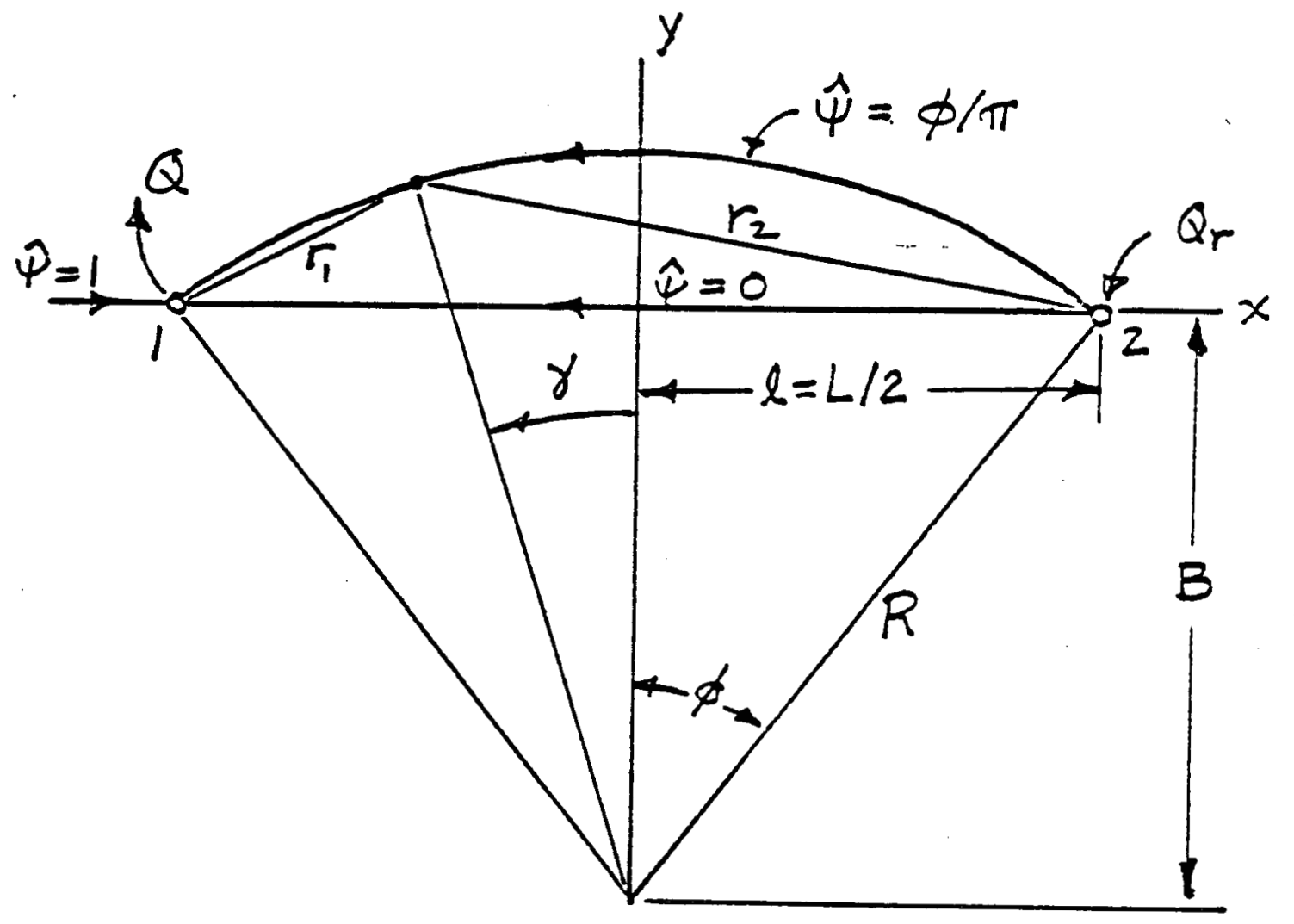

FIGURE A-1. POLAR CODRDINATE SYSTEM FOR THE - equal flow case. 
When $\gamma=\phi$, (A2) gives the travel time to the pumping well or

$$
a(\hat{\psi})=\frac{Q \tau_{\omega}}{n H L^{2}}=\frac{\pi}{\sin ^{2} \phi}(\sin \phi-\phi \cos \phi)
$$

Equation (A3) gives the dimensionless travel time between the wells as a function of $\hat{\psi}$; this result is used for a in (4). similarly, the $w$ flow integral is evaluated from (Al) as

$$
\begin{aligned}
& \omega=\int_{s_{0}}^{\bar{s}} \frac{d s}{[u(s)]^{2}}= \int_{\gamma=\phi}^{\bar{\gamma}} \frac{R d \gamma}{v_{\gamma}^{2}}=\frac{1}{L}\left(\frac{n H L^{2}}{Q^{2}}\right)^{2} b(\bar{\gamma}, \phi) \\
& b(\bar{\gamma}, \phi)=\frac{\pi^{2}}{2 \sin ^{5} \phi}\left[\frac{\bar{\gamma}+\phi}{2}+\frac{\sin \bar{\gamma} \cos \bar{\gamma}}{2}+\frac{\sin \phi \cos \phi}{2}\right. \\
&\left.-2 \cos \phi(\sin \bar{\gamma}+\sin \phi)+(\bar{\gamma}+\phi) \cos ^{2} \phi\right]
\end{aligned}
$$

Here $\bar{\gamma}$ indicates the position of the pulse along the streamline corresponding to $\phi=\pi \hat{\psi}$. At a given time the position $\bar{\gamma}$ is found by solving (A2) for $\gamma=\bar{\gamma}$ when $\tau=t$; this is done iteratively using the program listed in Appendix $c$. When $\bar{\gamma}>\phi$ the pulse for a given streamine has moved into the pumping well; in this case $\omega$ (or b in (4)) was calculated from (A4) using $\bar{\gamma}=\phi$. If dispersion is neglected, the concentration is found from (5) using (A3) to find $d \hat{\psi} / d a / a=T$ :

$\frac{d a}{d \hat{\psi}}=-3 \pi^{2} \csc ^{2} \pi \hat{\psi} \cot \pi \hat{\psi}+2 \pi^{3} \hat{\psi} \csc ^{2} \pi \hat{\psi} \cot ^{2} \pi \hat{\psi}+\pi^{3} \hat{\psi} \csc ^{\psi} \pi \hat{\psi}$ 


\section{SD-BWI-TI-073}

The concentration $\hat{c}$ is then found by assigning values of $\hat{\psi}$ between 0 and 1 , calculating $T=a$ Erom $(A 3)$ and $d \hat{\psi} / d a$ from (A5). 


\section{APPENDIX B \\ Graphical Evaluation of $\tau$ and $\omega$}

The flow integrals $\tau$ and $\omega$ can be determined from a graphical construction of the streamline pattern. This approach is necessary in the unequal flow case where the analytical description of the flow field is very complicated. The streamline pattern for $Q_{r} / Q=\beta=2 / 3$ (see Figure 1 ) was constructed by standard superposition of the ray streamlines of the appropriate source and sink strength. If each streamtube has a flow $Q_{0}$ and width $w(s)$ as a function of the distance along the centerline of the steamtube, $s$, the velocity is

$$
u(s)=0 /(\mathrm{nH} w(s))
$$

and then the flow integrals are expressed as

$$
\begin{aligned}
& \tau=\int \frac{d s}{u}=\frac{n H}{Q_{0}} \int u d s \\
& \omega=\int \frac{d s}{u^{2}}=\left(\frac{n H}{Q_{0}}\right)^{2} \int w^{-2} d s
\end{aligned}
$$

These integrals were approximated by measuring the width of the streamtubes at intervals $\Delta s$ along each of the streamtubes and summing the appropriate quantities ( $w \Delta s$ or $w^{2} \Delta s$ ). The integrals were evaluated for each streamtube for intervals in $\hat{\psi}$ of 0.1 at the pumping and well normalized as in (3). These data for a $(\hat{\psi})$ and $b(\hat{\Psi})$ at the pumping well were then fit to polynomials of the form

$$
\text { In } a=\sum_{n=0}^{4} a_{n} \hat{\psi}^{2 n}
$$




$$
\text { Is } b=\sum_{n=0}^{4} b_{n} \hat{\psi}^{2 n}
$$

These expressions were then used in the integrations of (4) to find the concentration in the pumping well. Note that (BI) gives only the value of $b$ at the pumping well, $b_{w^{*}}$ In general, $b$ will increase with time as the pulse approaches the well along a given streamline; this behavior was represented in the form

$$
b / b_{w}=\left\{\begin{array}{cc}
(T / a)^{m}, & T \leqslant a \\
1, & T>a
\end{array}\right.
$$

where $\mathrm{m}$ is a positive exponent to be specified. $a$ and $b$ from (3I) and (B2) were then used in (4) to find c.

In order to evaluate the above graphical procedure, the flow net evaluation was done first for the equal fiow case $\beta=1$ and the results were compared with the exact analytical approach in Appendix A. 


\section{APPENDIX $C$}


This program calculates the concentration (Cw) of

tracer appearing In a woll as a tunction of the time

The user is asked to supply several inftlalizing parameters. and the values of $T$ (time) desired. First. the all-purpose parameter epsilon (wnich accounts tor dispersion effects) is input.

Then, you are asked to input the last value of ps 1 and the Increinent of psi to use. (p) of psi and the Increment of psi to use. cpst coning trom. accurate, and detinitely takes longer. (We are aroroxinating accurate and det initely takes longer (We are anproximat accurate. Good result.s a e obtalned In a reasonable annint of time with dpsi between 0.05 and 0.2 (Use strallor apsi for smaller values ot epsilon.)

The output of the prorram, a table of values of time (T) and concentrotion (CW), can be sent elther to a file

ctor firtier nrocessing. plotting et.cis or directiv to the I line printer. For oach value ot T'a set ot values lor the parameter y (equal tiow onjy!) which analytically determines $y$ ( function of PSI and T): and NICe; In which Y is set to (T)a) in where m is a usel-supplied constont. (ilsualivi.0)

Hext, the prograin asks how to get the maglc sets ot values $A$ and $B$, used. In the concentration integral. For the equal low case, these can be tound dicctiy as a simple analytical function of psi. In lineoual flow froblelis however these valijes calinot be deterinined exactiy, so youl rust supply instead tive coefticients tor a polynomial approxination io trie cinctions.

Now that Inftjalization is completed, the brocirail will read in values of $p$ troin the termlinal ana calculate and jisnlay cw.

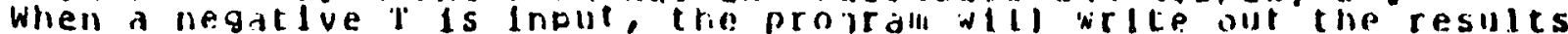
Con the printer or to n tlie (alled lable. dat) alli stop. To lonk

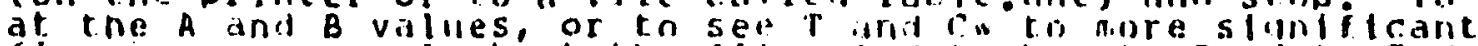

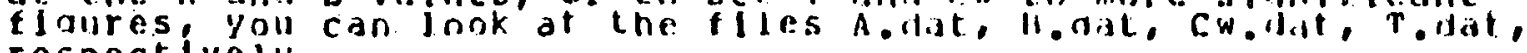
respectively. 
c

C

c

Inttialize useful varlables and open output flles

FII,ES USED;

A. dat:

Cw.dat:

T. int:

A Values

A values

Calculated Cws

cemporary storage of Ws

real last, m

double prectsion pl

dImens lou a $(0: 4), b(0: 4), 111 \mathrm{ag}(2)$

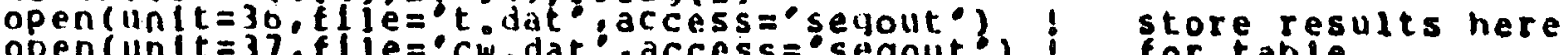

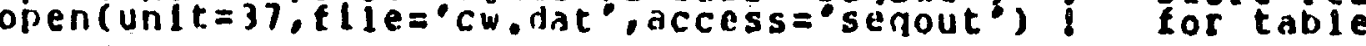

$p 1=3.141592653589793$

innum $=-1$ l counts munber of ts supplied 
Read in user-supplled parameters

wr 1 te $(5,1)$

format (t5.'Input epsilon: $\bullet 6)$

read $(5,2)$ eps
tormat $(\mathrm{t} 6.4)$

find out what range of psi values to use

wr 1 te $(5,3)$.

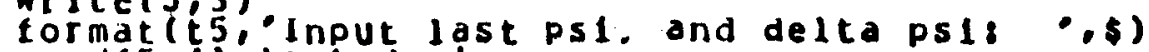

read(5.4) last, dps 1

tormat $(3(t 6.4))$

step evenly, starting at stepsize/2

flrst $=\operatorname{dps} 1 / 2$

number $=(1 a s t-t \mid r s t+d p s 1) / d p s 1$ : how many values of ps 1

outpil, In table form, can go elther to a flle or to the

line printer. Herefwe find out willch is desired, and open

the appropriate devlce as unit 38 .

40 Write(5, 13 ) Where do yoy want the output to go? $11, t 10$,

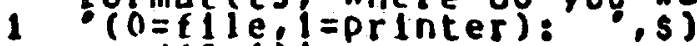

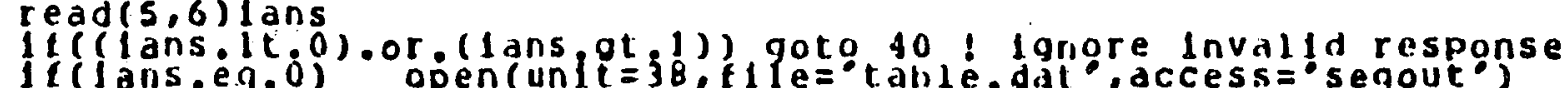

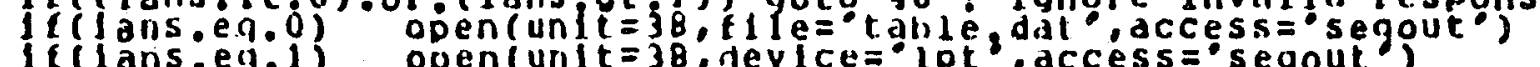

c Ycan be calculated in two ways: a nices slmple method

(using a user-speclifed fudqe tactor): or a more complex

exact method (which works only for the equal flow case)

ilce process is to be is ed, read lil the tudqe tactor now.

wrt e $(5,14)$

$1 \quad$ (ormat (t5: Exact or nlce

read $(5,6)$ iytlay ! set'1yf 1 ag: $n$ exact, 1 nice

If(cytlag.1t.0) or. (1yflag.nt.1)) goto bo ! had resuonse 1 (Iyflag.eq.0)goto so)! exact, no fuaye tactor

15

write $(5,15)$

read $(5,2) \mathrm{m}$ input flase factor M:, 5$)$

FInd which values of a and b lo use and set flag

c

wr $11 e(5,5)$

( $\quad 50$

$\mathbf{1}$

formatcis. Exact or curve flt valles tor a? , 1,010,

6

(O=exact $t=E(t):$ : 1 :

torinat

()

torinatiti

If ( (1ans.1t.0).or (1ans.gt.1) goto so ! Ignore fnvalld gesnonse

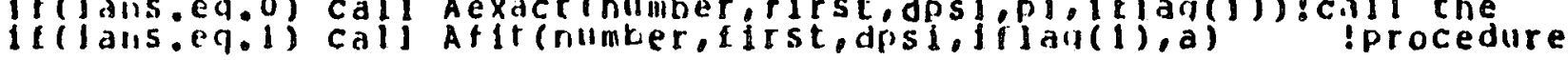


wite $(5,7)$

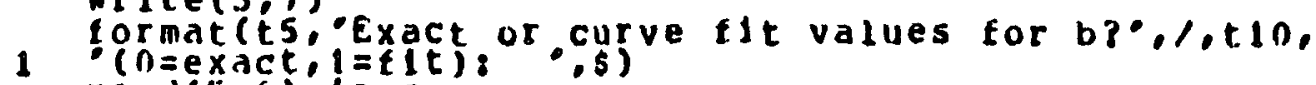

read (5ac)

If ((1ans $1 \mathrm{t} .0)$ or (1ans.gt.1)) goto 60 ! lgnore Inval1d response

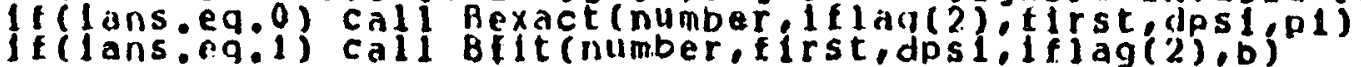

8 frite $\left(5,{ }^{B}\right)$, r o stop, input a negative value for $\left.t^{\circ}\right)$

c MAIN LOOP:

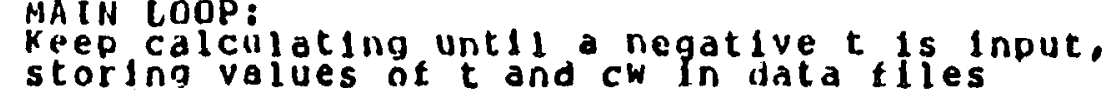

$70 \quad$ wrte $(5,9)$
$90 \operatorname{trmat}\left(t^{\circ}\right.$

10 tormatifitioj

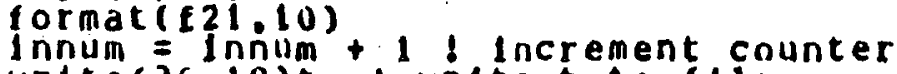

write $(36,10)$ ! wite to tile

$\mathbf{c}$

as soon as a neyative $t$ is input call a rolltine

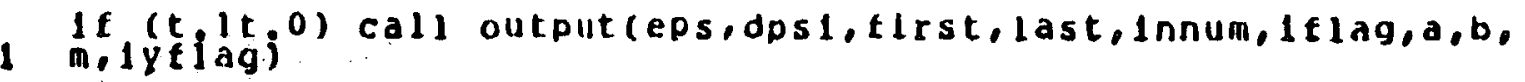

get $y$ values for thls

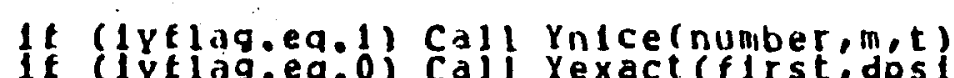

cexact (first, dps , number,t,pl)

$\stackrel{c}{c}$

Here we flnally call the routlne to get the

number we are atter.

result $=c w(t, d p s i$ number, pleps)

write $(37,10)$ result : Nite $C_{w}$ to flle

wrje 5 fil) result and terminat

for inat $\left(t, 0,{ }^{\circ} \mathrm{C} w=, \$ 9.5\right)$

goto io loop torever untll nerative $t$ is input.

end! eno of palin progran 


\section{Subroutine Aexact (number, first,dps $1, p 1,121$ )}

This routine caiculates values for the parameter a using an exact equation. The As, one tor each value ot psi usede are written to lile a.dat

in the program. The user specifles whether this routine

or the approxlmate version "Afit" is to be used. Note

that the exact metnod works onif for equal fiow probiems.

Initialize variables and open output flle

double precision pi

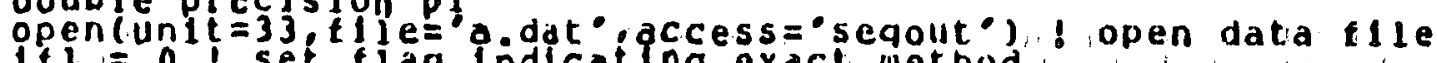
$1 t==0$ ! set tiag indicating exact method

psi: = Itst! Initjalize psi

loop through all vallies of psl, calculating an a for each

do $11=1$ number \& now many values we need

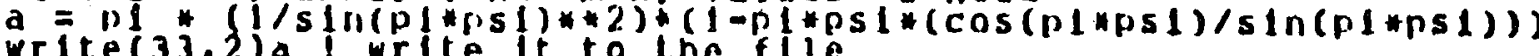
wite

format (f 21 . 10$)$

psi 1 psi 1 dpsl Increment ps!

close $(11 \mathrm{n} 1 \mathrm{t}=33)$ ! close (1)

return

end 
Subroutine Bexact (number, Ifl, first,dps1,D1)

Bexact gets values for b wlth an exact equat 1 on.

Bs ar: written to the tlle B.dat for later use

Plag. It l. Is set so the output rout ine knows that

exact b values were used. Remember the exact

method can be used only tar equal fíow.

double precision phi,b,pl

If $1=0$ : set flog: exact values

open (unit $=34, t j l e={ }^{\circ} \mathrm{b} . \mathrm{dat}^{*}$, access='seqout ${ }^{\circ}$ ) d open b.dat

c

loop: get a b: write $1 \mathrm{t}$ out

do $11=1$ inumber.

pht $=p I *(\operatorname{trst}+(1-1) * d p s 1)$ font $=$ ps $1 * p 1$

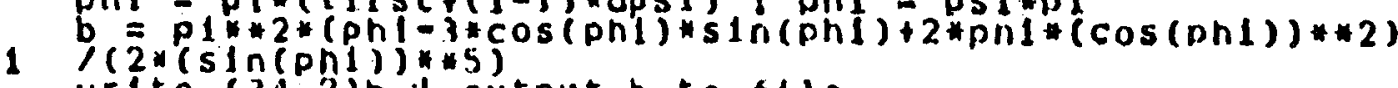

write (34,2) ! outpit b to flle

continue

close(unlt $=34)$ b close output flle b.dat

return

end 
Subroutine Af 1 (number,first, dps $1,1 \mathrm{fl}, \mathrm{a}$ )

This routine opens the tlle a.dat and calls

the rout ine oft which does a polynomial curve

fit using user-supplied coefficlents. The five

coetricle

In the orray a' and $r$ lag if is set to indicate

the use of approximote values.

dimension a $(0: 4)$ ! coefflclent array

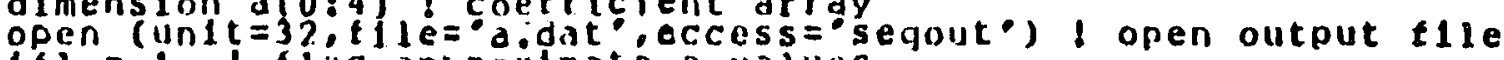
If $1=1$ I1 iag apmoxlmate a values

call. Fit (number first,dpsl,a) ! cali routine to generate As

close (unlt=32) !clean up

return

end

\section{Subroutine Bitt (number, first, dps $1,1 \mathrm{f} 1, \mathrm{~b}$ )}

This rout ine is identical to Afit, but the flle bodat is opened finstead of a.dat. Coefliclents are returned in

dimension b(0:4) ! array to hold 5 coetelclents

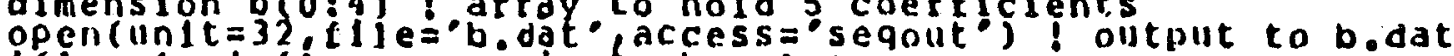
if $1=1$ ! ilag approximale b values call Fit (number, first,dps1,o) ! get " values close $(u n I t=32)$

return 


\section{Subroutine fit(number,tirst,dpsi,c)}

Fit reads in 5 coefficients and uses them to approximate elther a ur b. depending on whether it was called by A $1 \mathrm{t}$ or ofit (in the first case, data goes to o.dat, In the seconil, hedat). The variable c is equivalent to elther a or b. whichever is approprlate.

dimension $c(0: 4)$ array of curve fit coefficlents do $101=0,4$ ! get them one at a time

writeis

cormat (t.5.' [nout a coetefejent')

read $(5,2) c(1)$ ! read one in

2 format(fi, $\left.{ }^{4}\right)(1)$ iwrlte it to the terminal to confirm

c calculate c andwrite 1 t to flie

linlt 32 has been opened by our caller

as the correct output flle (a.dat or b.dat)

pst = first ! go through oll psis

do $31=1$. nimber

$\operatorname{temp}=n$

do $4 \mathrm{n}=0.4$

the coefflcients are tor a polynomial fit in

psi squared

temp $=$ temp $+c(n) * D s 1 *(2 * n)$

the natural log of the data was used to determine coetficlicits, so we must take the exponentlal of the result

result $=\exp (t e m p)$

write(32,5itesilt! write to a.dat or b.dat

format. ( 21.10$)$

psi $1=$ os $1+$ dps 1

continue

return

end 


\section{Subroutine Ynlce(number, m,t)}

Here we calculate y values with sleazy-but-nice formula (using only a and a user-supplied fudge factor). Actually ne write out not Y ltself but a close relative $(\equiv b y)$. The walues are put in (guess what?) w.dat.

define varlables and open useful data tles

real m double precls lon $y, b$

open (unit=33, f 1) e =

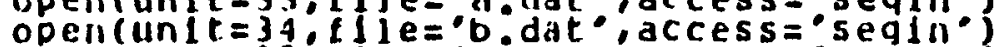

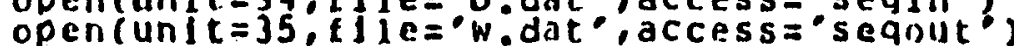

If $1=1$ ! set flag: approximate y valies

Do $1,=1$, nunner? 1 y for eacli os 1

rearl(33,2)a! read in

2 tormat $( \pm 21.10)$

$Y=(t / d) * m$ in is ludge factor

If(t)/a),gt, l $) y=$

$w=b * y$ iget $w$

write 35,23$)_{w}$, w ite to to

1

continue

tidily cjose all files...

close (un $1 \mathrm{t}=33)$

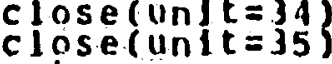

return

end 
Subraut Ine Yexact( 1 Irst,dps 1, number,t,pl)

This rout ine gets exact values for y (and w)
using a rather messy equation (equal fiow only).

c

define variables and open flles

double precis lon ph1, temp1, temp2, w, gamma

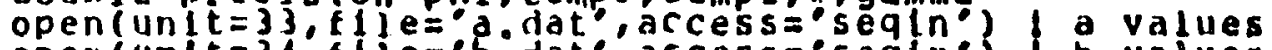

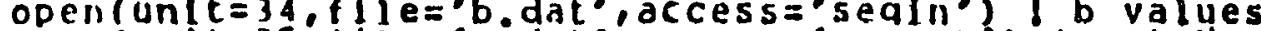

open(unit $=35$, t $11 \mathrm{e}=$ 'w.dat', access='seqout')! put Ws here

$1 \in l=0$ ! flagexact $Y$ values

Do $1=1$ = loguthrough all psis

read $(33,2) a$ : get a

2 tormat $(2)$ ito

phj $=$ p *(ijrst.t(1-1)*dps l) ! phl = pI*ps!

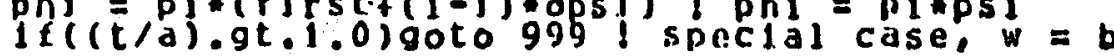

invoke function to find gamma, used in

calculating y $(w)$

gammo = Gappr(phI, $a, t)$

templ $=(($ gammatphl $) / 2+(\sin ($ gamina $) * \cos ($ gamina $) / 2)+\sin (p h t) *$ 2 cos(phi) $\cos (p h 1) * 2 * \cos (p h 1) *(\sin (g a m m a)+\sin (p n 1))+(g a m m a+p h i) *$

temp? = pi**2/(2*sin(pn1)**5)

$w=t e m p 1: t \in \operatorname{tin} 2$

999 goto 1000

$1000 \quad$ if (w.1e.0.001)w = 0.001 ! "uply things nappen $1 \mathrm{w} w=0$ writei35:2jw write to wodat

1 returne! get next w. return

end 
Function Goppr(phi,a,t)

c returns on approximation to gamma

double preclsion gamma

oldt $=t / a$

oldx $=0$

10

$x=2 * 010 t-1$

$g=p h(x x$.

$1 / 2=(\sin (p h 1)+\sin (g)-(p h 1+q) * \cos (p h 1))$

oid $x=x$

$x=x^{+}(0)$ de $\left.-f\right) / 2$ \& get new $x$

20

goto io ! check again

return

Funct Ion Cw(t,dps1, number,pl,eps)

Approximate the integral for the concentration $\mathrm{Cw}$ double preclsion temp,c,pl,w,aaa $c=0$

open (unlt $=33, \mathrm{f} 11 \mathrm{e}={ }^{\circ}$ a. dat ${ }^{\circ}$, access $==^{\prime} \operatorname{seq}\left(n^{\circ}\right)$

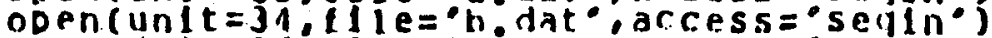

orencunit $=35$, flie $={ }^{\circ}$ w. dat ${ }^{\circ}$, access $=$ "serjin $^{\circ}$

do $1=1$. number

read $(33,2)$ a

read( $35 \% 2) \mathrm{W}$

formatifi.io

Iemp $=$ expi $-((a-t) * * 2,(4$ *eps*k))

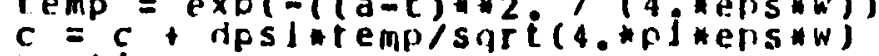

continue

$c W=c$

retiurn

enal 
Subrout

(yflag)

$c$

$c$

Qutput prints the results in a table, either

dimension 1 tigg(2) ! flags tora b: exact or approx djmension a $(0: 1) !$ coefticients
dimension $b(0: 4)$ ! b coefliclents

open flles with results

close (unt $t=36)$

close (unt $t=37)$

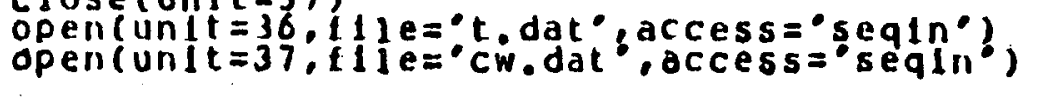

unit 38 has already been opened as elther

table.dat or Lpt:

wr It e ( 38,1$)$ eps.dpst f irst, 1 ast

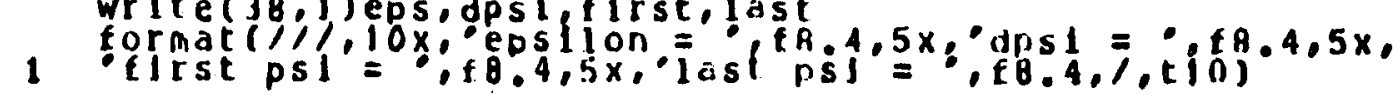

$1 \mathrm{f}$ exact a b values, say so

fe(It lag(1), eg:n) write $(38,5)$

If (1fiag( 29, eq.o) Write $(38,6)$
formatit

It curve tit was used, print coefilclents

It ( If $\operatorname{lag}(1), e q .1) w r 1 t e(38,1)(a(1), 1=0,1)$

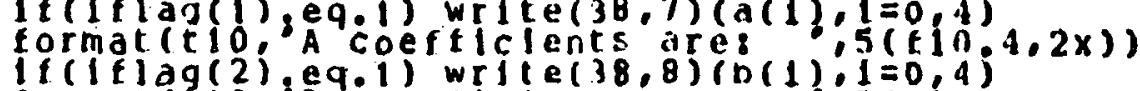

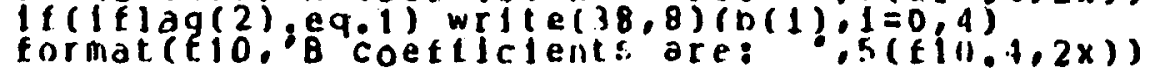

tell how $y$ was calculated

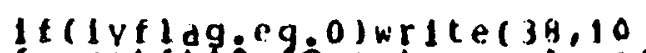

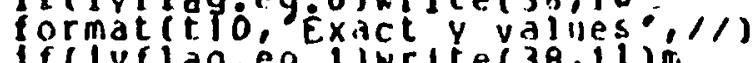

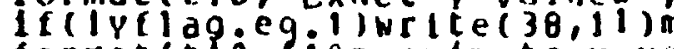

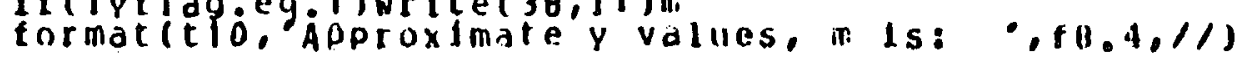

print heacter for table

wrtte $(30,9)$
format $\left(t 31, \cdot T^{\circ}, 12 x,{ }^{\circ} \mathrm{C} w^{*}, 1\right)$

read in and Cw from todit and Cw.dat:

do $2, \frac{1}{1}=1$ Innum ! Innum = of Ts supplied

read $(36,4) t$, get $t$

format.

read $(37,4) \mathrm{cw}$ ! get $\mathrm{Cw}$

wilte $(3 \dot{8}, 3) t, \dot{c} w$ ! make table

tormat $(25 x .1 k .1,5 x, 1.8 .4)$ 
APPENDIX D

TABLES OF TYPE CURVE DATA 


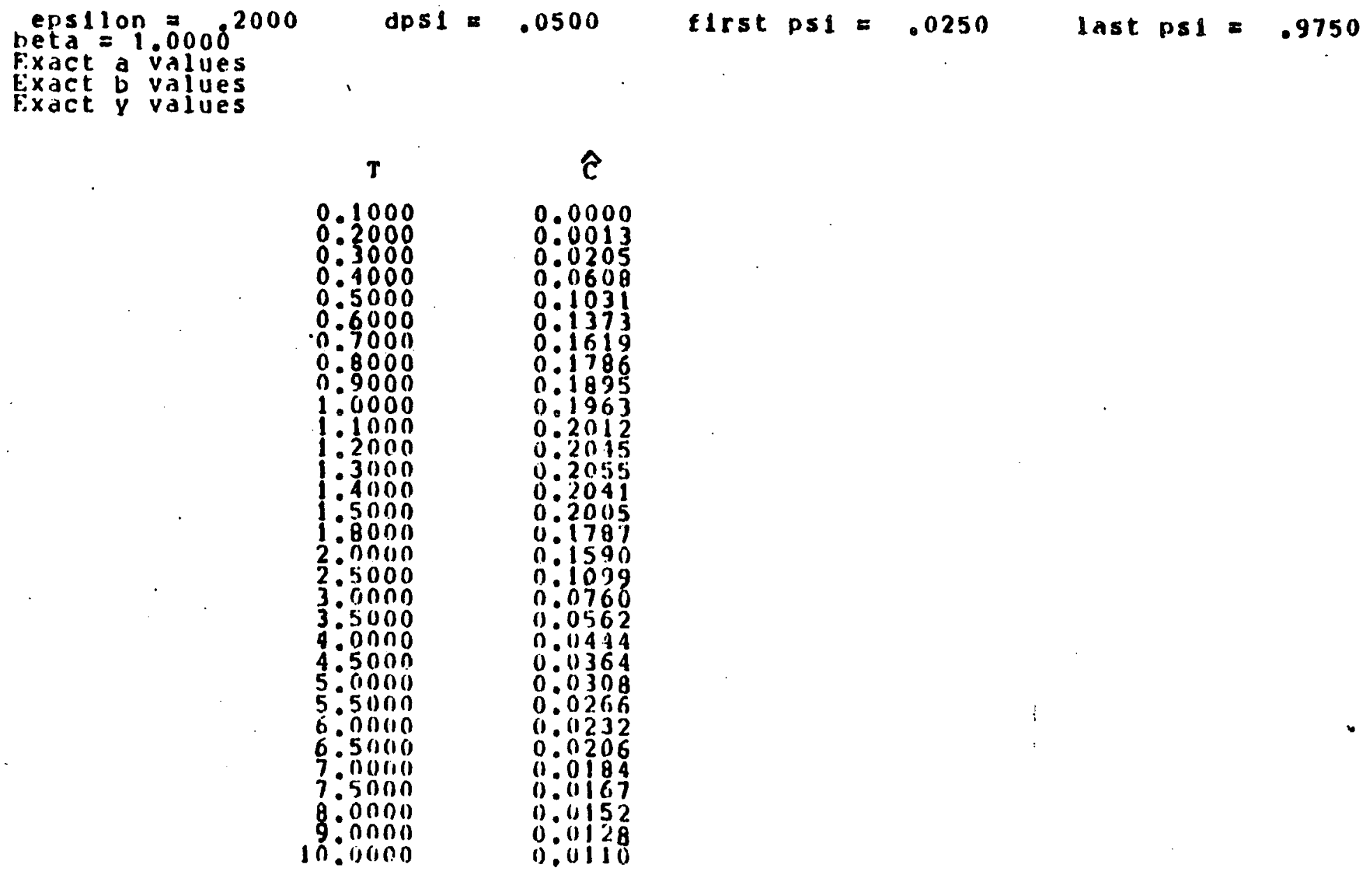

Tab. 1 


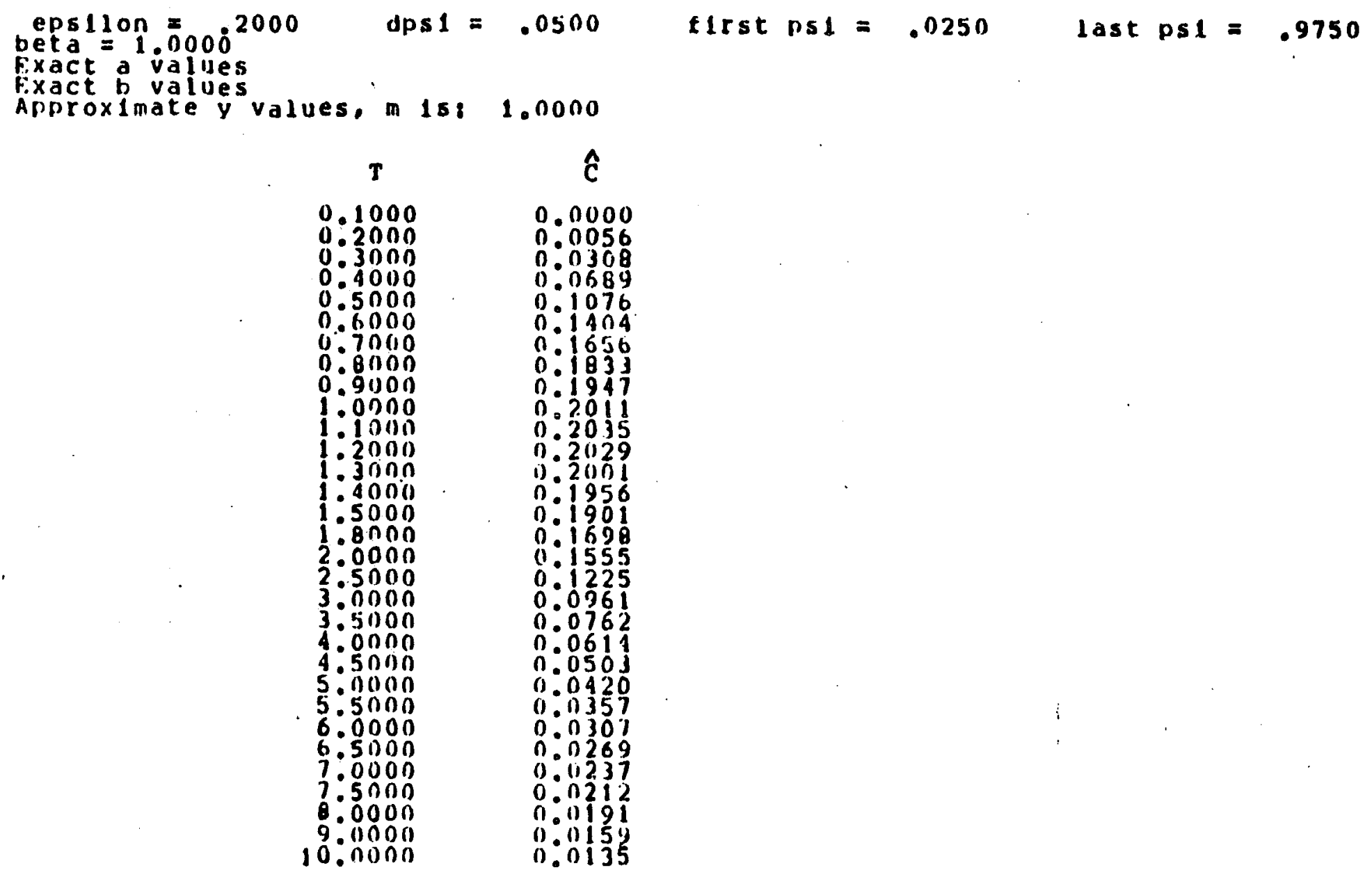

号

Tab. 2 


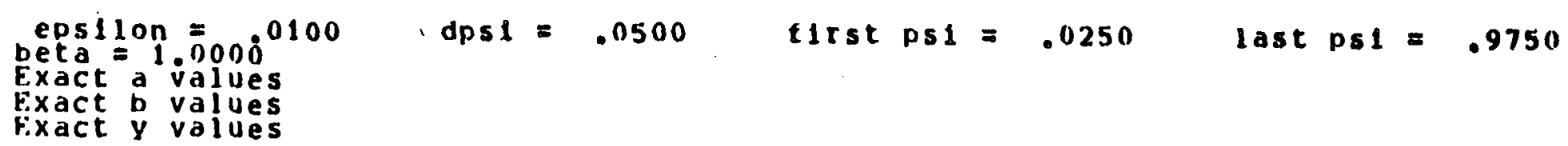

\begin{tabular}{|c|c|}
\hline $\mathbf{T}$ & $\hat{\mathbf{c}}$ \\
\hline 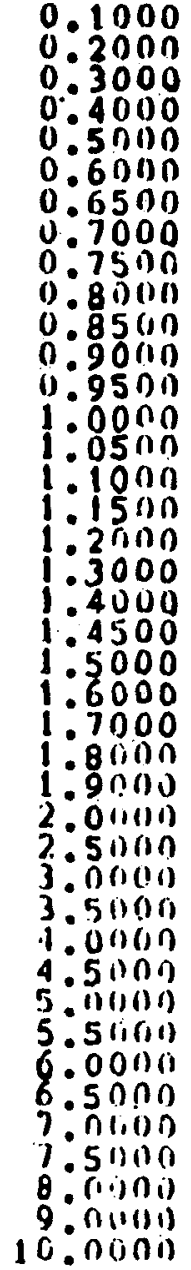 & 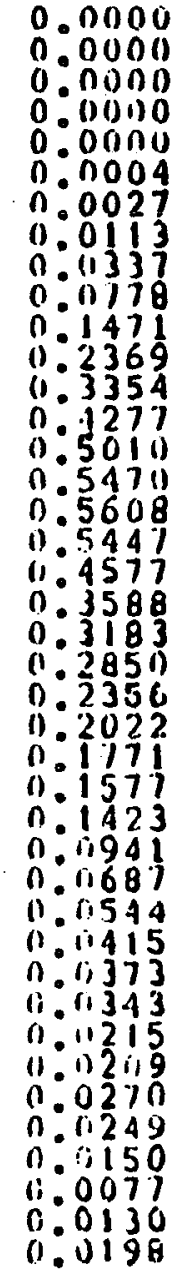 \\
\hline
\end{tabular}




\begin{tabular}{|c|c|}
\hline 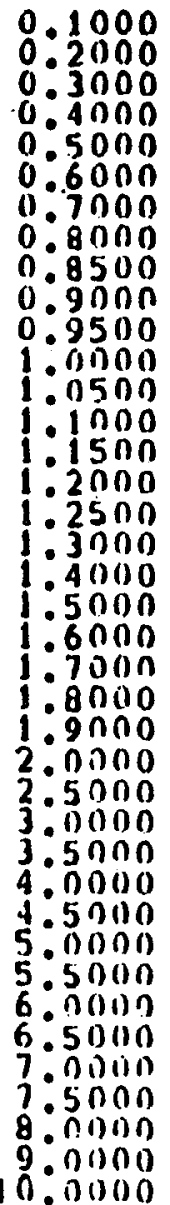 & 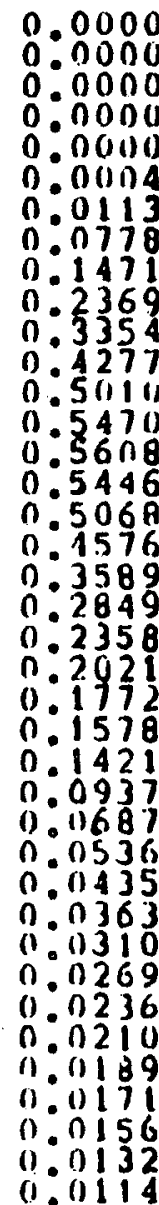 \\
\hline
\end{tabular}

Tab. 4 


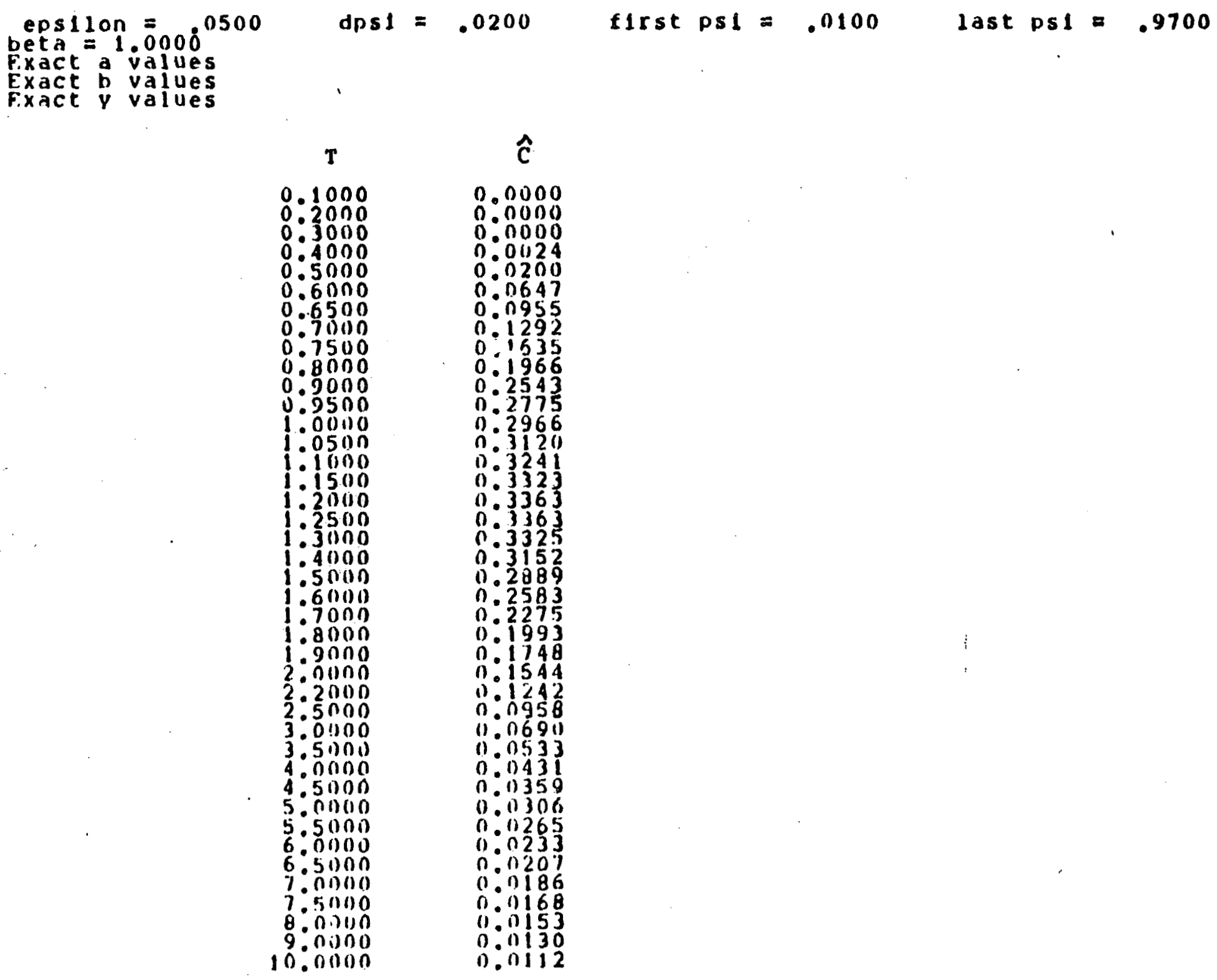




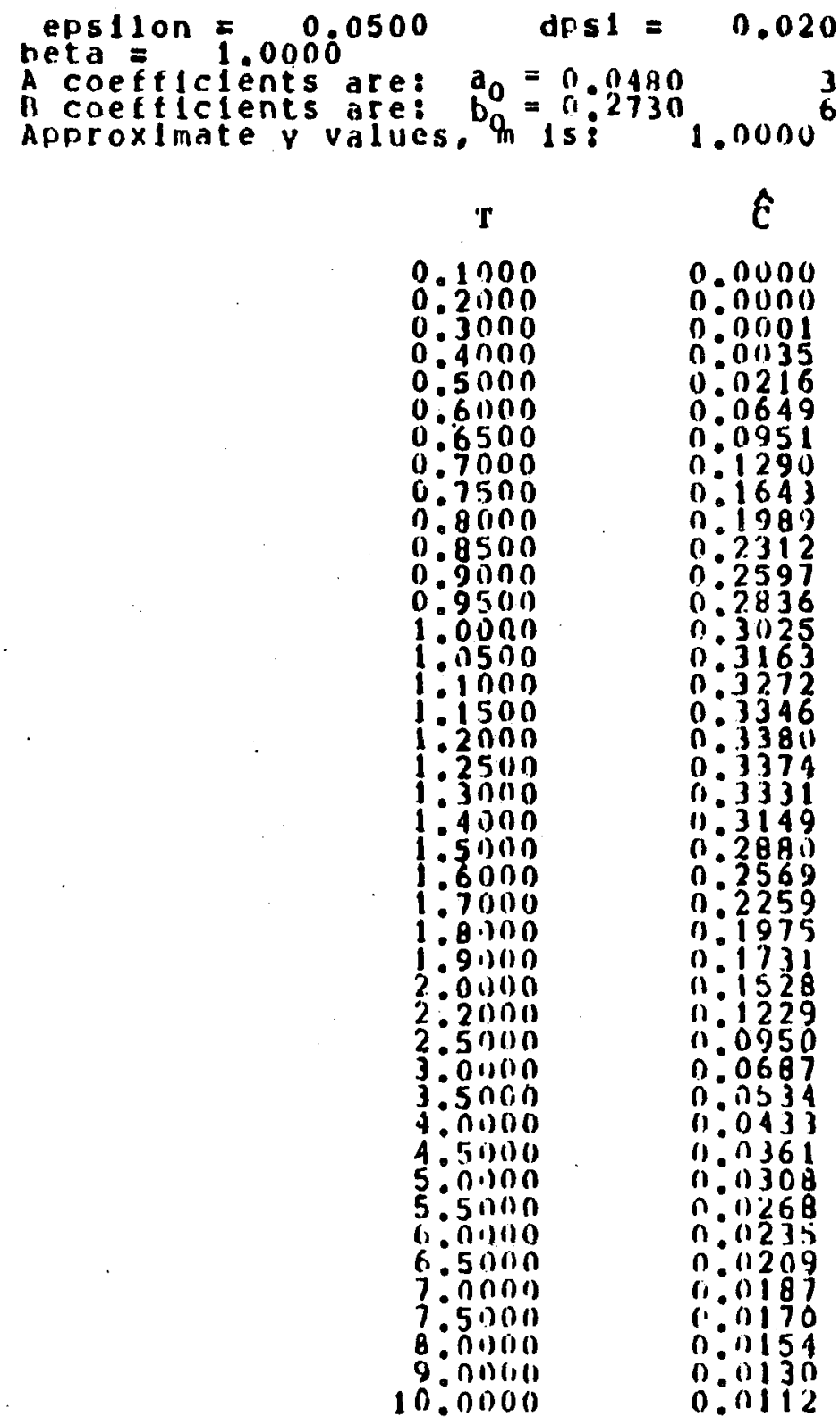




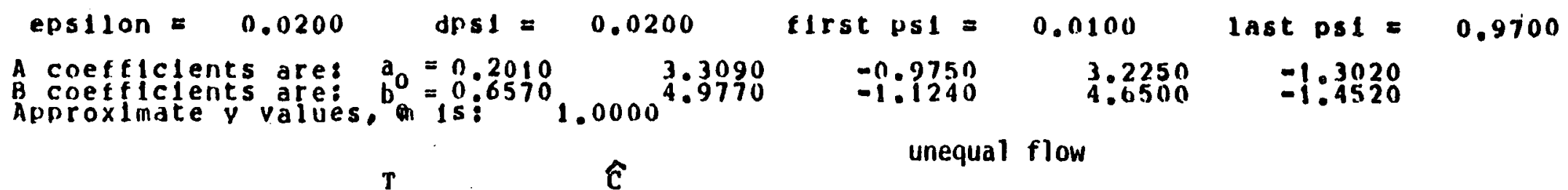

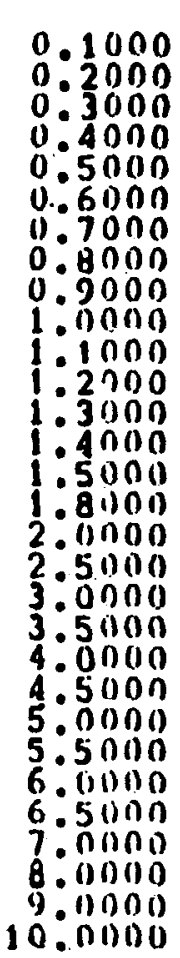

u. 0000

a. ก000

0.0000

). nuna

0.0000

0.0114

0.0110

0.1115

0.2033

०० 122

0.4160

0.4092

0.2706

0.2112

0.1294

0.0927

0.071

0.0570

0.0471

0.0399

0.11302

0.0269

0.0250

0.196

(1) 6 \%

0.0144 


\begin{tabular}{|c|c|c|c|c|c|}
\hline $\operatorname{eps} 110 n=$ & $\operatorname{ars} 1=$ & 0.0200 & f|rst ps| $=$ & 0.0100 & last ps $1=$ \\
\hline $\begin{array}{l}\text { A coefflcients are: } \\
\text { B coeficients are } \\
\text { Approximate } v \text { values. }\end{array}$ & $\begin{array}{l}a_{0}=0.2010 \\
b_{0}=0: 6570 \\
m: 8\end{array}$ & $1.0000^{3.3090} 4970$ & $\begin{array}{l}-0.9750 \\
-1.1240\end{array}$ & $\begin{array}{l}3.2250 \\
4.6500\end{array}$ & $\begin{array}{l}-1.3020 \\
-1.4520\end{array}$ \\
\hline
\end{tabular}

0.0000

0.0000

0 nono

$0.010 n 9$

0. (0) 77

0. 0279

0.0652

0.1157

0

0.2627

i. 2915

$0: 3102$

0.3201

0.3196

(1.) 2934

0.2719

0.2243

0.1364

0.0945

0.0573

11.0473

(1). 1399

. 0345

. 1345

(1.) 302

1.1126

0.11239

0.0216

0.0196

r. 0165 


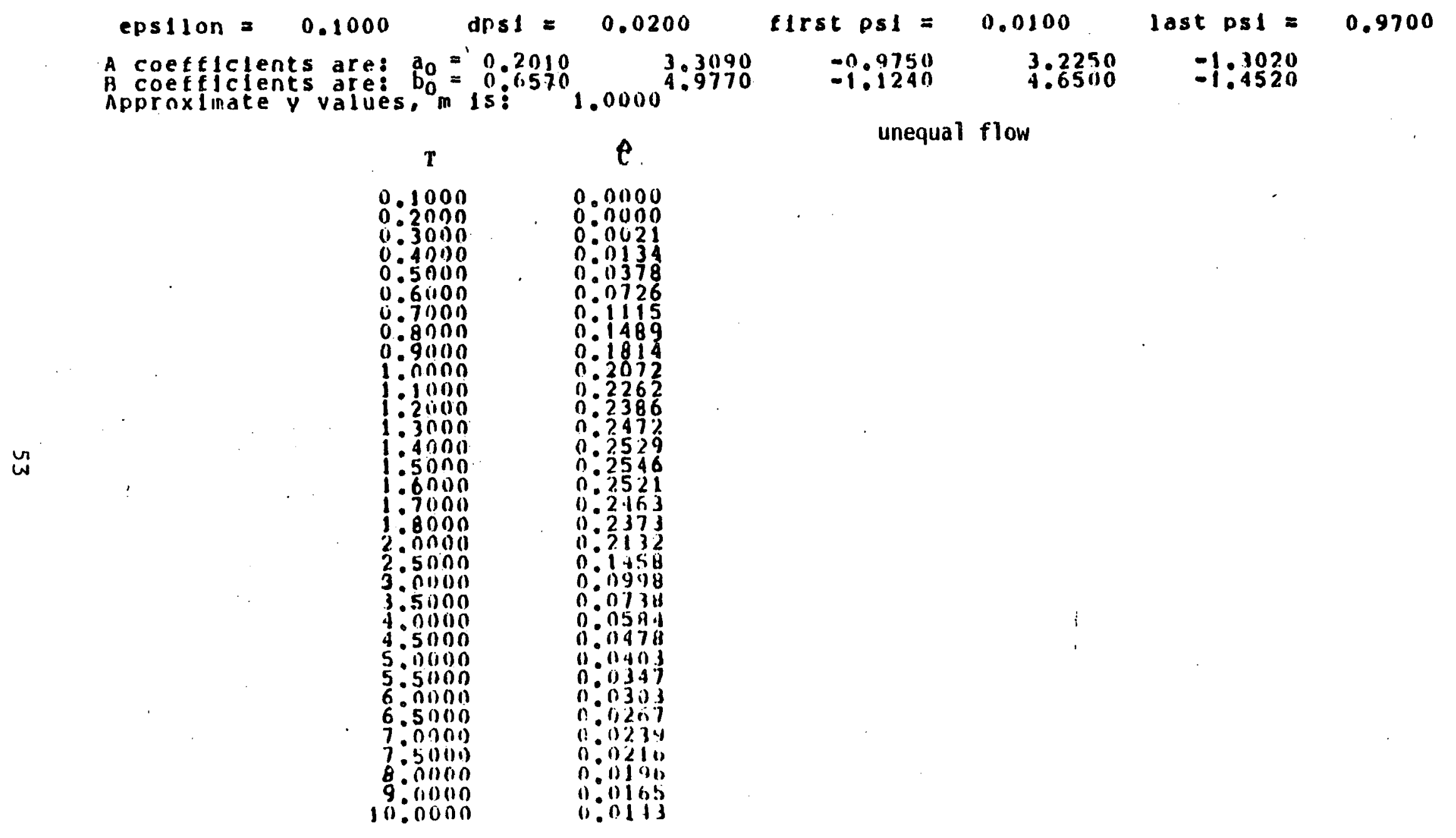

Tab. 9 


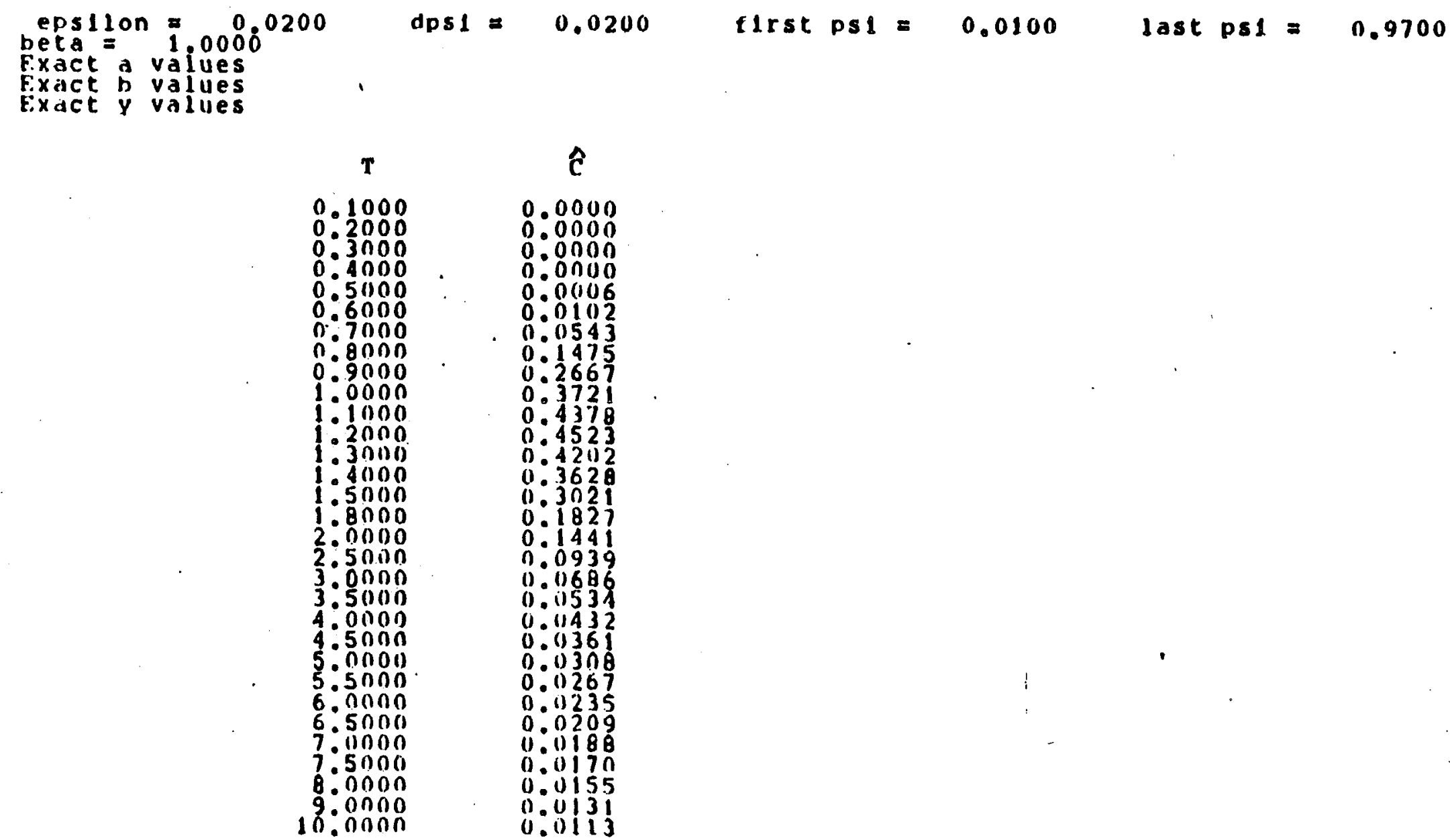




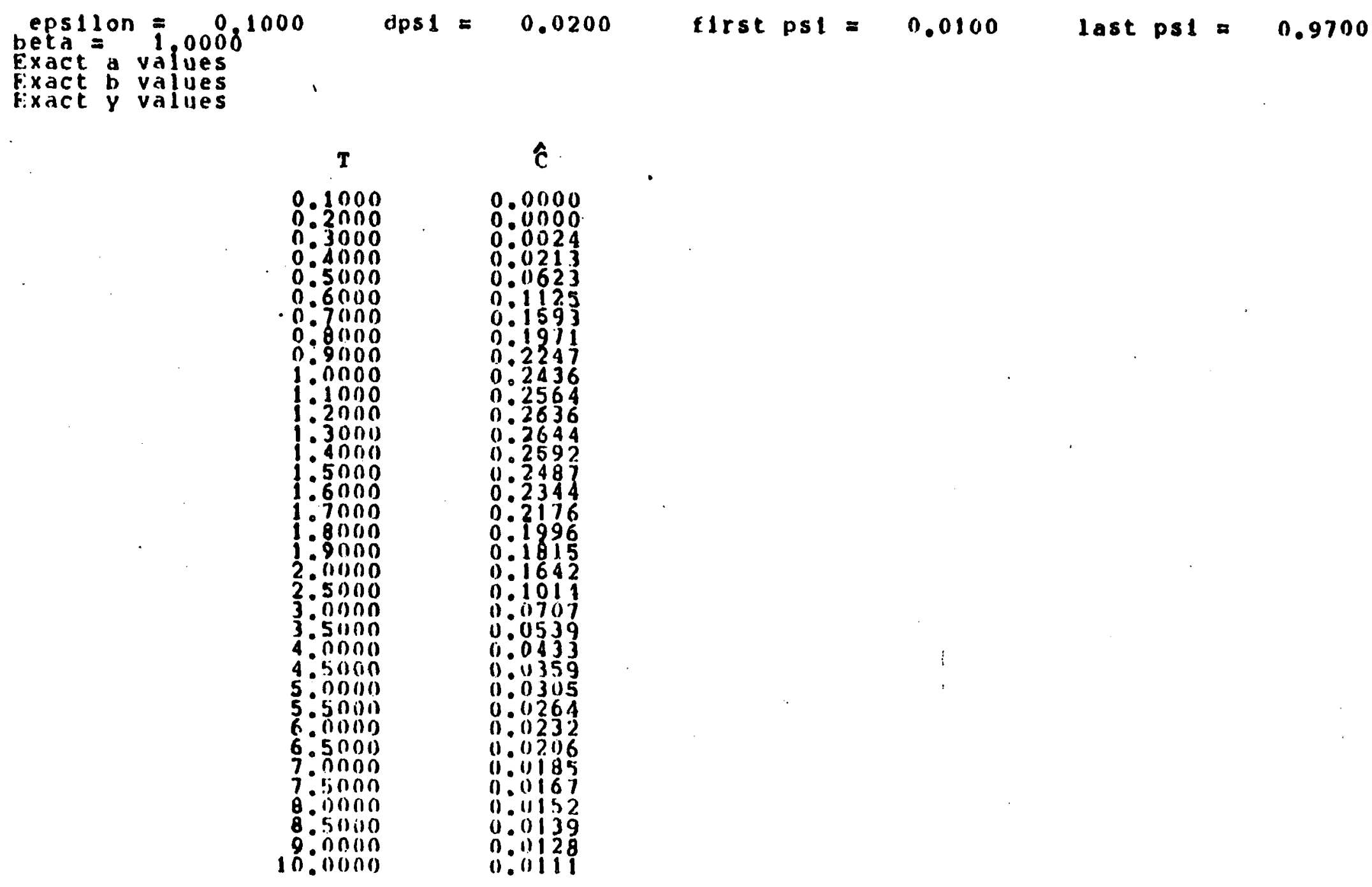

号

Tab. 11 


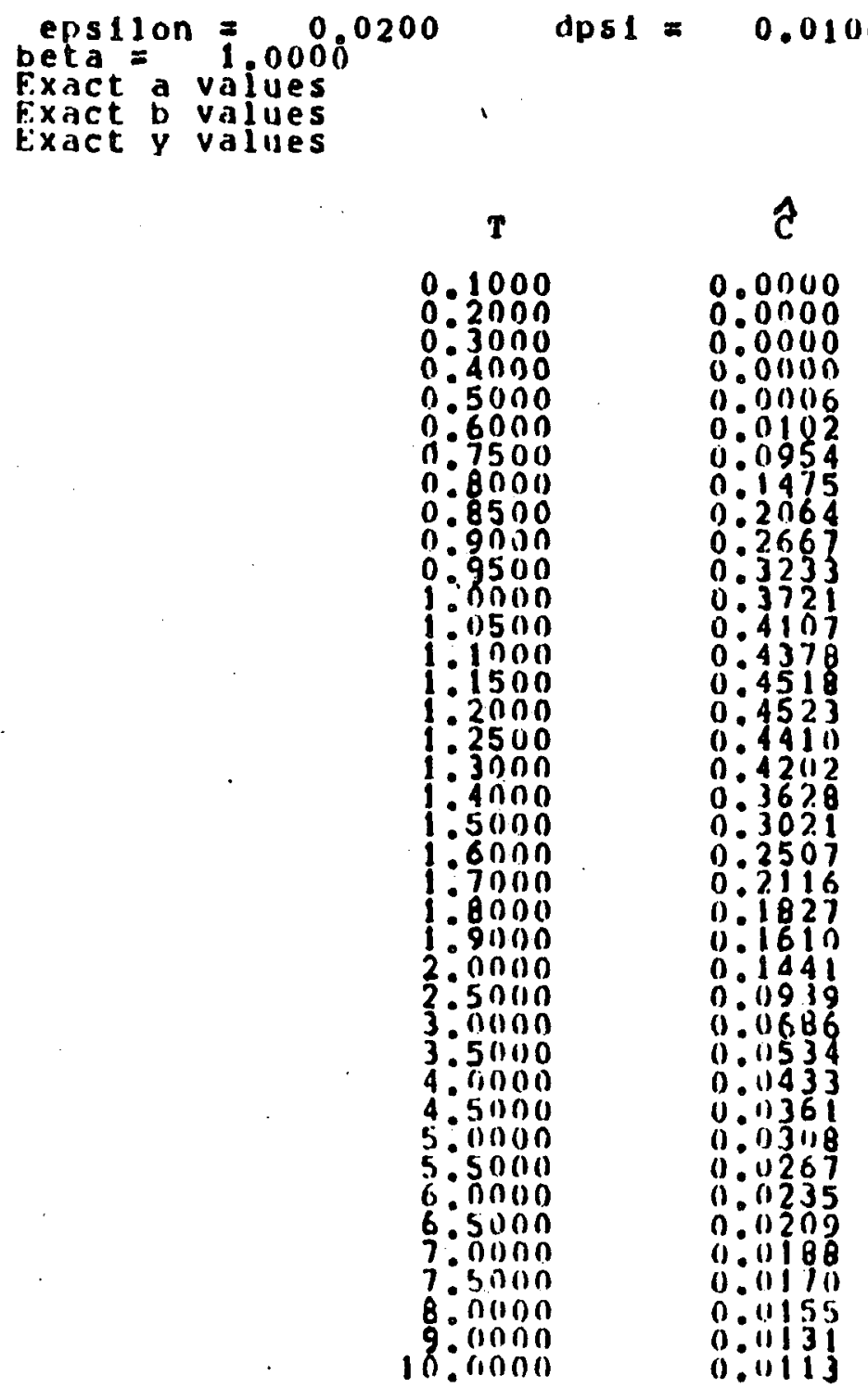




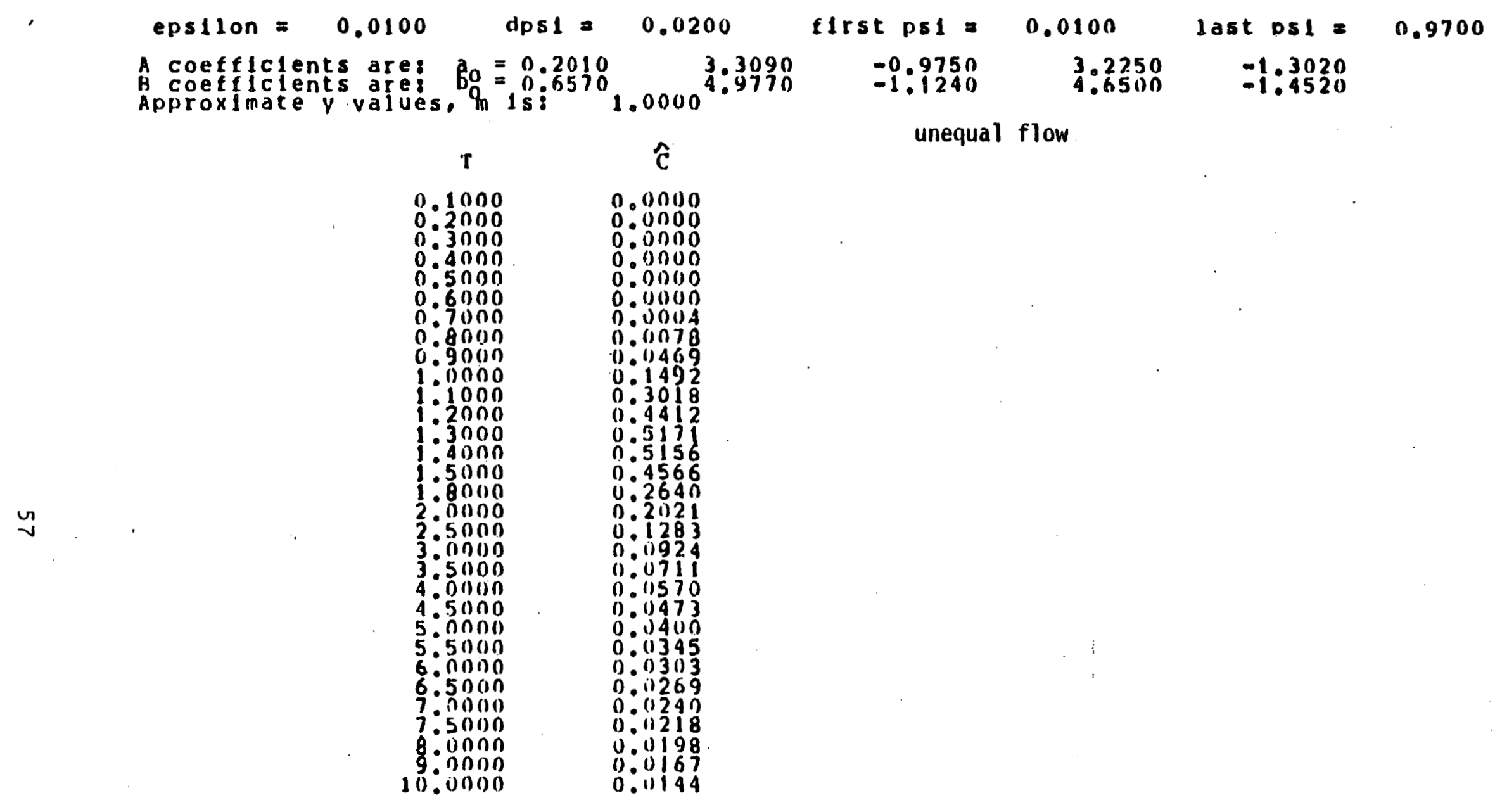




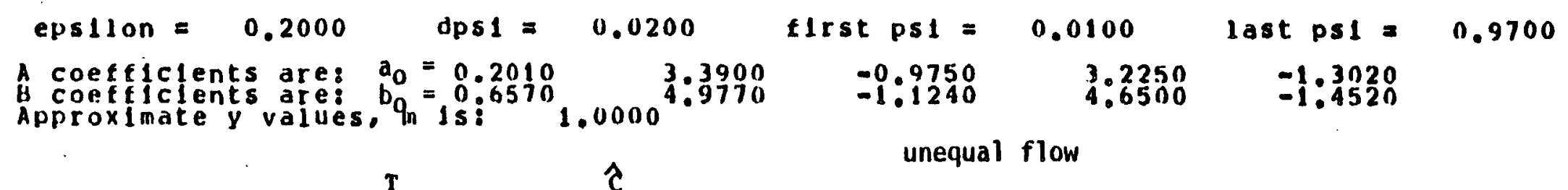

\begin{tabular}{|c|c|}
\hline 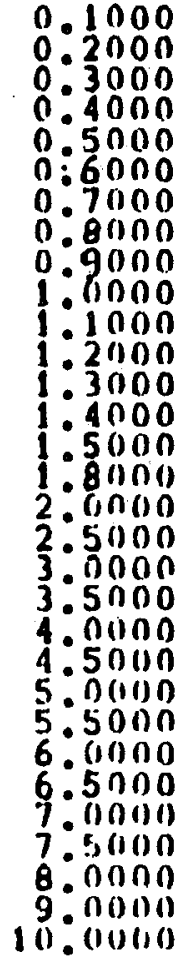 & 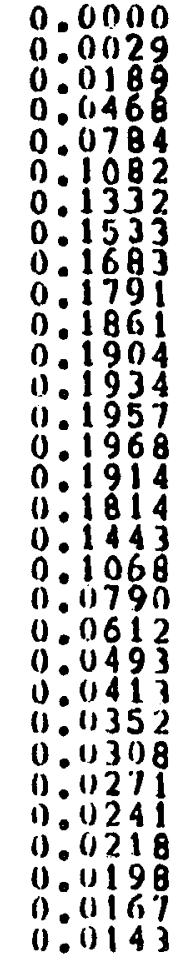 \\
\hline
\end{tabular}




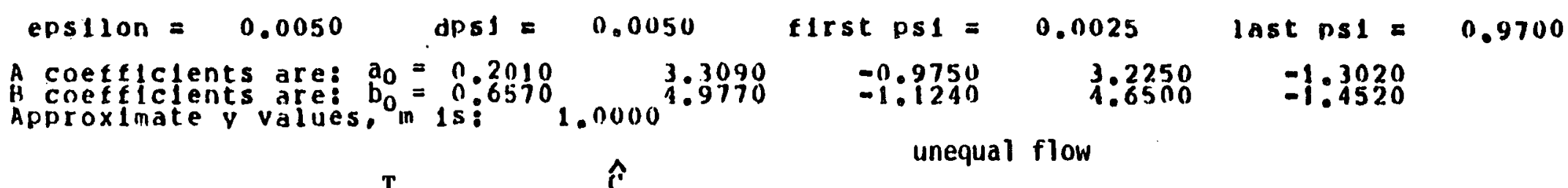

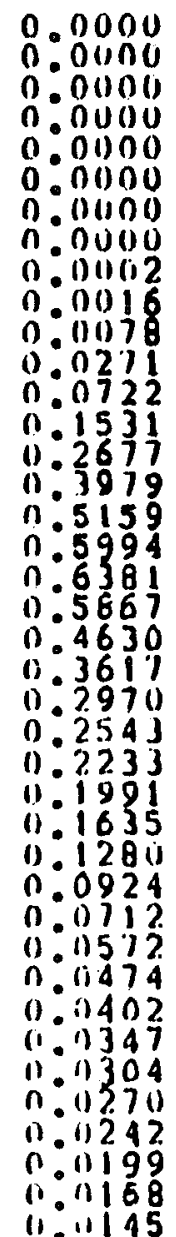




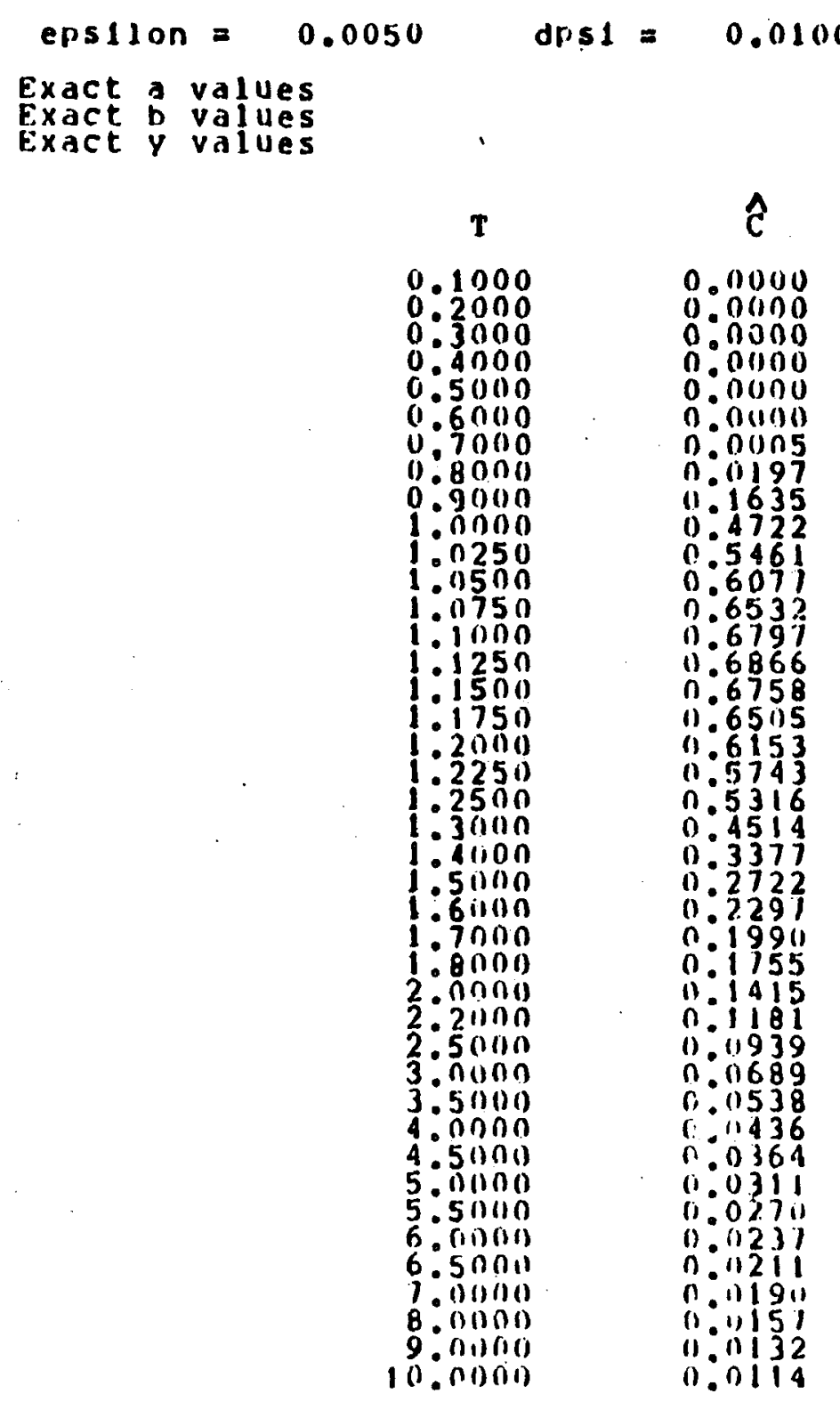



$\operatorname{epsi10n}=$
$\operatorname{des} 1=$
0.0100
$\operatorname{trst}$ os $1=$
0.0050
last psl=
0.9750

\section{Exact a values \\ F.xact $h$ values}

Fixact y values

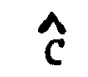

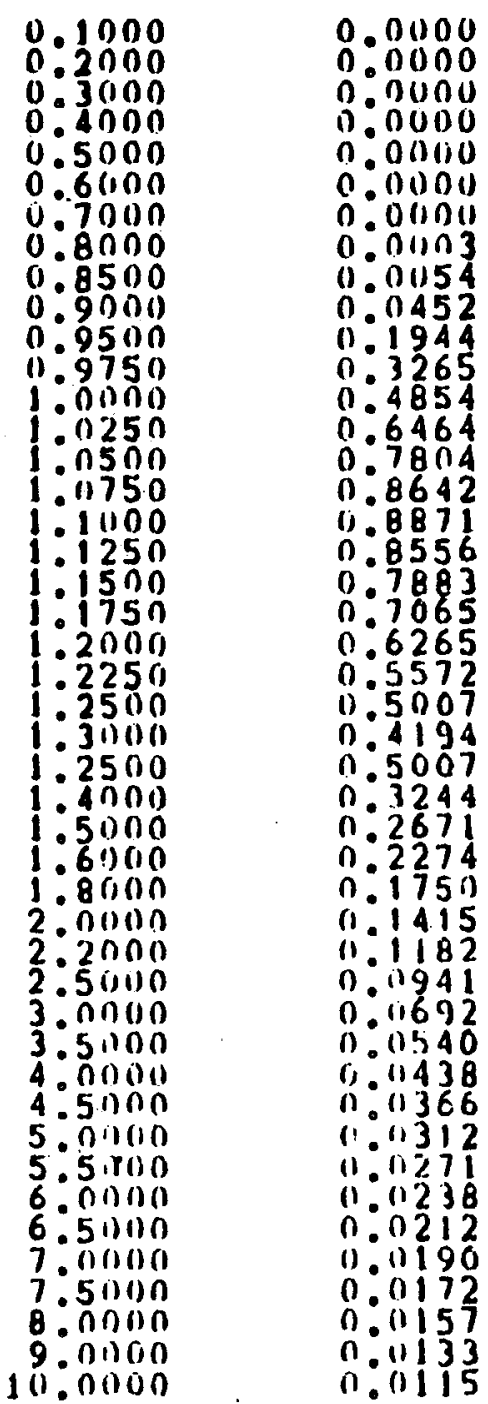

